\title{
La CNT y el Sindicato Vertical. La quimera de la libertad sindical con Franco
}

\author{
Ángel Herrerín López *
}

\section{RESUMEN ABSTRACT}

El intento de salir de la profunda crisis en la que estaba inmersa la CNT en la década de los sesenta, y la creencia en la evolución democrática del régimen franquista, llevó a viejos militantes cenetistas a firmar un acuerdo con representantes franquistas que convulsionó el mundo libertario de la época, y repercutió negativamente en la reorganización del movimiento tras la muerte del dictador.

PALABRAS CLAVE CNT, anarquismo, sindicato vertical, "cincopuntismo".
The attempt for getting out of the deep crisis in which CNT was immersed in the sixties, and the belief that the Franco regime, would develop to democracy led the old CNT activists to the signing of an agreement with Franco representatives which threw the libertarian world of that time, into confusion and had a negative impact on the reorganitation of the movement after the death of the dictator.

\section{KEY WORDS}

CNT, anarchism, vertical union, "cincopuntismo".

Hemos asistido, en las últimas dos décadas, a un esfuerzo improbo por parte de la historiografía contemporanista española para proyectar luz, allí donde sólo existían reflejos, sobre el período franquista, una de las

* Becario. Formación Personal Investigador del MEC. Adscrito al proyecto de investigación: "La formación del nuevo Estado. Componentes políticos y sociales del primer franquismo". PB970772. Universidad de Alcalá de Henares. 
partes más duras y, por su proximidad, más importante de nuestra reciente historia.

Aunque es cierto que el camino recorrido es enorme, no es menos cierto que quedan todavía vías sin explorar. En unos casos por la imposibilidad de acceder a las fuentes necesarias, ya sean oficiales o privadas; en otros, por la dificultad intrínseca del tema; o, simplemente, por la falta de relevancia que, para la sociedad actual, representan determinados temas. Quizá el compendio de éstas, y otras que no se exponen aquí, nos lleve a una de las sombras que, a mi modo de ver, resulta más acusada, y que corresponde a la falta de estudios que, para el citado período histórico, existe sobre la Confederación Nacional del Trabajo. Sería necesaria ampliar la investigación sobre su historia orgánica, su lucha antifranquista, su evolución ideológica, sobre el devenir de sus militantes, en definitiva, sobre todo aquello que nos ayude a comprender que sucedió con la organización anarcosindicalista una vez pasado su momento de esplendor, que nos ayude a entender las causas que han motivado la situación de postración en la que se desenvuelve el movimiento libertario en la actualidad.

No han faltado las explicaciones que, de un modo genérico, se han aportado sobre el ocaso de la CNT, como la que realiza, en el epílogo de su interesante libro, De la calle al frente, el profesor Julián Casanova, que pone especial énfasis en los cambios socio-económicos que tienen lugar en España desde la década de los sesenta, dejando en segundo plano otras cuestiones más próximas a la historia intrínseca de la organización cenetista. Sin embargo, son precisamente, estas causas relacionadas más directamente con el devenir de la CNT las que, a mi modo de ver, necesitan de un estudio con detalle, me estoy refiriendo: al duro enfrentamiento interno, la represión sistemática que sufrieron sus cuadros dirigentes, la relación de la Confederación con las organizaciones internacionales obreras, que se tradujo en una grave falta de ayuda económica, las relaciones entre el interior y el exilio, el inmovilismo ideológico...En definitiva, todas esas cuestiones que han sido continuamente esgrimidas por la historio grafía, y que en muchos casos han alcanzado la categoría de tópicos, pero que carecen de una investigación con profundidad.

El presente articulo pretende dar un paso más en esta reconstrucción histórica, desentrañando uno de los últimos episodios protagonizado por la central anarcosindicalista durante el franquismo, cuyas repercusiones se harán sentir, en el seno de la organización, hasta bien entrada la transición democrática en España, y que todavía, hoy en día, es motivo de polémica en el mundo libertario. 
Las negociaciones que tuvieron lugar entre militantes de la CNT y representantes de la Organización Sindical franquista, en el primer lustro de los años sesenta, tienen su origen, por un lado, en los cambios que la sociedad española empezó a experimentar tras el abandono de la etapa de autarquía económica que llevó a cabo el régimen franquista hasta finales de los años cincuenta. Los nuevos planteamientos económicos supusieron, además de otras realidades en la sociedad española, el resurgimiento de la reivindicación obrera, cuestión que hizo albergar, en no pocos luchadores antifranquistas, la esperanza en un final próximo de la dictadura. Se retomaba la idea, abonada en décadas anteriores, de que la vuelta a las libertades tendría su primer acto en la democratización sindical.

Antiguos militantes cenetistas creyeron que era posible la reconversión democrática de los sindicatos verticales, y no dudaron en llegar a un pacto con los burócratas falangistas -este "episodio" de la reciente historia cenetista recibió el nombre de "cincopuntismo", en referencia a los cinco puntos que recogía dicho acuerdo-. Entre otros motivos, a los confederales les alentaba el poder sacar a la CNT de la situación de abandono en la que se encontraba después de largos años de lucha clandestina contra la dictadura.

El término de las negociaciones, que impuso el dictador a mediados de 1966, no significó, en contra de la opinión general, el fin del intento "cincopuntista", sino que tuvo su continuidad en la actuación de la organización del interior y, por supuesto, su repercusión en el exilio. Analizar su génesis, evolución y fin son el objetivo de las siguientes páginas.

\section{LA SITUACIÓN A PRINCIPIOS DE LOS SESENTA}

En los años finales de la década de los cincuenta y principios de los sesenta, el régimen de Franco inició un crecimiento económico que supuso un cambio decisivo en la sociedad española de la época, cuya repercusión social y política fue de una importancia vital en el devenir del propio régimen $y$, consecuentemente, para el futuro de nuestro país.

En efecto, en 1957 con la entrada de un nuevo gobierno, y el desembarco en él de los ministros pertenecientes al Opus Dei, se puso en marcha la liberalización de la economía española. En sus primeros dos años, dicha liberalización, tuvo una implantación errante, debido, en gran medida, a la resistencia de los sectores que, desde el régimen, seguían apoyando el intervencionismo estatal. Fue con el llamado Plan de Estabilización, obra de Navarro Rubio en 1959, cuando se dio el impulso definitivo 
para el cambio de rumbo de la economía española. Atrás quedaban los años de la autarquia económica que habian supuesto la miseria para los trabajadores y el empobrecimiento del país ${ }^{1}$. Determinante para la salida de esta situación había sido el apoyo de Estados Unidos y del Vaticano que, con sendos pactos firmados en 1953, dieron el espaldarazo político y, en el caso del primero, la ayuda económica imprescindible, para el mantenimiento del régimen franquista en España. El desarrollo económico español tuvo su repercusión exterior en la entrada de nuestro país en organismos internacionales tales como: El Fondo Monetario Internacional, la Organización Europea de Cooperación Económica y el Banco Internacional de Reconstrucción y Desarrollo. Su plasmación interior tuvo su principal referente en el crecimiento industrial acompañado del desarrollo del sector turístico; lo que supuso una serie de cambios importantes, ya no sólo en la economía, sino en la sociedad española: la migración interior, la evolución de la estructura de la población activa - con un incremento en los sectores de la industria y servicios, y una disminución en el correspondiente a la agricultura--, el aumento de la presencia de la mujer en el mundo laboral, el incremento de la población asalariada, etc. ${ }^{2}$.

Esta nueva situación llevó implícita la realización de cambios importantes en las relaciones de trabajo, que se plasmaron a través de la Ley de Convenios Colectivos de 1958. Este nuevo marco de relaciones laborales fue importante para el desarrollo económico capitalista de España, ya que necesitaba, para potenciar su crecimiento, desprenderse del "corsé" que imponía el Estado; que había tenido, hasta la fecha, un papel primordial en las negociaciones laborales con los trabajadores. Ahora, con la aplicación de la nueva ley, las conversaciones se realizaron directamente, en el seno del sindicato, entre los representantes de empresarios y trabajadores ${ }^{3}$; de este modo, los primeros pudieron ver incrementados sus beneficios, y los segundos, su salario a cambio del incremento de la productividad. La aplicación del Plan de Estabilización supuso, en su inicio, la recesión de la economía española que, una vez más, tuvieron que sopor-

En 1951 el poder adquisitivo de los salarios era de un 40\% respecto a 1936. En 1953 era un $20,3 \%$ inferior ai mismo año. Véase ponencia de Ricard de VARGAS-GOLARONS: "La huelga del primero de mayo de 1951 en Cataluña», Tusell, J., ALted, A., MATEOS, A., (Coord), La oposición al régimen de Franco (Tomo I volumen 2), Madrid, UNED, 1990. Los valores de la Renta Nacional y la Renta Per Capita de 1935, no se recuperaron hasta 1952 y 1954 respectivamente. Véase, MOLINERO, C. E Ysàs, P., Productores disciplinados y minorias subversivas, Madrid, Siglo XXI, 1998, pág. 44.

2 Véase las diferentes tablas estadísticas en, Molinero, C. y YsÁs, P., op. cit, págs. 51/61.

3 Esta representación era real en el caso de los empresarios; no asi en el de los trabajadores, ya que sus representantes pertenecian a la burocracia falangista, \%, por lo tanto, no habia sido elegidos por ellos. La situación cambió a mediados de los 60 , cuando las grandes empresas pudieron negociar su convenio propio y los trabajadores controlaron el Jurado de Empresa. 
tar, de forma primordial, los trabajadores ${ }^{4}$. A partir de 1961 se empezó a superar esta recesión, dando paso a un fuerte crecimiento económico. Pero también supuso, desde 1962, un gran incremento de la conflictividad laboral y el inicio de un nuevo activismo obrero, que los partidos y organizaciones clandestinas interpretaron como el pistoletazo de salida en la carrera que tendría como meta el fin del período franquista y el inicio de un nuevo régimen.

Para los grupos que formaban parte del franquismo, la nueva situación también supuso un enfrentamiento, en este caso por el poder, ya que la burocracia nacional sindicalista se vio desplazada por la irrupción de los tecnócratas del Opus Dei, e intentó, aprovechando la creciente conflictividad laboral, que el sindicato vertical ocupara un lugar destacado en la nueva política de desarrollo económico. Solís, secretario del Movimiento, buscó este protagonismo, desde 1965, tanto en el exterior como en el interior de nuestro país; fuera de nuestras fronteras entabló relaciones con la Confederación Internacional Obrera de Sindicatos Libres y con la Organización Internacional del Trabajo; y en el interior, contactó con representantes socialistas, comunistas y cenetistas. Fue entre estos últimos donde Solís obtuvo mejor acogida, ya que la CNT, en esos momentos, también necesitaba recuperar el "poder" perdido entre los trabajadores. Atrás había quedado la etapa más importante de la Confederación en la clandestinidad, entre los años 45 y 47 , cuando la organización contaba con unos treinta mil afiliados que cotizaban regularmente, y su estructura se extendia, prácticamente, por todas las regiones de España. Pero con el fin de los años 40 , vino el declive irremisible de la organización anarcosindicalista: principalmente, por la fuerte represión que desencadenó el régimen franquista contra los sindicatos, y en especial contra la CNT con la desarticulación de varios de sus comités nacionales, decenas de regionales y locales 5 ; y, en segundo lugar, por la falta de ayuda exterior, como consecuencia de la escisión en el seno de la organización en el exilio, al quedar éste, en su mayoría, en manos de la fracción purista enfrentada con la política que llevaba a cabo el sindicato anarcosindicalista en el in-

\footnotetext{
${ }^{4}$ Los trabajadores perdieron un $23 \%$ en su nivel de renta, y el paro aumentó en un $34 \%$. Véase. Tusell, J., Manual de Historia de España, Madrid, Historia 16, 1990, pág. 704.

${ }^{5}$ Antonio Bruguera, miembro del comité nacional que cayó en noviembre de 1947, realizó un informe en el que, tras detallar las diferentes redadas en las que fueron detenidos los miembros del comité nacional, señala que «...la perseverancia en la lucha nos ha ido permitiendo decir «a rey muerto, rey puesto". Pero hace mucho tiempo que temiamos la llegada del dia en que esta militancia, por tantos conceptos heroica, tropezaría con las dificultades de no encontrar compañeros competentes que pudieran asumir la responsabilidad de los cargos en los organismos superiores. Y, desgraciadamente, ese día llegó. La cantera está casi agotada...". Molina, J. M., El movimiento clandestino en España, 1939-1949, México, Editores Mexicano Unidos, S.A., 1976, pág. 230.
} 
terior. La CNT de España, al comenzar la década de los 60, estaba lejos de poder ser considerada como una organización mínimamente estructurada. La mayoría de sus militantes habían pasado, cuanto menos, dos veces por la cárcel en un breve espacio de tiempo: la primera, inmediatamente finalizada la guerra civil española como consecuencia de su participación en la misma; la segunda, por su actividad clandestina contra la dictadura. Una vez puestos en libertad, en los años 50 , un gran número de estos militantes antifascistas se recluyeron en su trabajo y familias, con la intención de reconstruir sus hogares deshechos; abandonando, de esta manera, cualquier actividad orgánica dentro de la Confederación, y limitando su compromiso a contactos o, en el mejor de los casos, reuniones, más o menos periódicas, con otros compañeros que se encontraban en la misma situación que ellos. Para otros militantes confederales se impuso la idea de salir del letargo, "inmovilismo» según sus palabras, en el que se encontraban inmersos. Esta reflexión se convirtió en acuciante al comprobar que sus "eternos enemigos», los comunistas, a través de su estrategia de penetración en los sindicatos verticales, estaban extendiendo sus redes de influencia allí donde antes estuvo el campo de actuación predominante para los libertarios, es decir, en los talleres, las fábricas y los sindicatos. Un grupo de antiguos militantes confederales, con un pasado sindicalista intachable, entendieron que la nueva situación del país, y una supuesta liberalización del régimen, propiciaba el inicio de unas negociaciones con altos mandatarios franquistas que podría llevar a la recuperación del anarcosindicalismo en España.

\section{ANTECEDENTES A LA NEGOCIACIÓN CINCOPUNTISTA}

Las conversaciones que en la década de los sesenta tuvieron lugar entre personalidades del régimen franquista y militantes de la CNT, fueron el colofón a los contactos que, prácticamente desde el origen de la Falange, tuvieron lugar entre sus dirigentes y miembros de la central anarcosindicalista. Esta serie de contactos tuvieron su justificación en la defensa de planteamientos afines, entre las dos organizaciones, tales como: su acerbado anticomunismo y su oposición a la existencia de partidos políticos; que los falangistas confundieron con una identificación ideológica de la que, en realidad, se encontraban bastante alejados. Además de esta supuesta identificación, los falangistas, una vez terminada la guerra, tuvieron la necesidad de apoyarse en personas que contaran con experiencia en la formación, estructuración y funcionamiento de los sindicatos para llevar a cabo la puesta en marcha del aparato vertical. También necesitaron militantes que ostentasen un supuesto prestigio entre los trabajadores, 
para dar visos de autenticidad a unos sindicatos que nacieron, por su propio origen, completamente desprestigiados.

Llegados a este extremo, hay que hacer una puntualización fundamental, en un tema tan delicado como el que nos ocupa, sobre lo que puede ser considerado como "colaboracionismo" con el régimen franquista. A este respecto, se debe diferenciar a la persona o grupo que ayudó y se integró en el nuevo régimen de forma voluntaria buscando exclusivamente su propio beneficio, de las actuaciones que, aún significando ocupación de cargos en las instituciones del nuevo Estado, tuvieron su origen en la coacción efectuada por el régimen o en la "obligación" que les impusieron, los mismos trabajadores, a ciertos compañeros en talleres y fábricas para seguir siendo sus representantes, y que, lejos de colaborar en la consolidación del nuevo régimen, utilizaron sus resortes para ayudar a otros compañeros que estaban siendo represaliados, o para intentar defender los intereses de los trabajadores frente a los abusos del patrón o de la Administración. Por supuesto que, tanto en una como en otra circunstancia se pueden encontrar, no sólo en la CNT sino en todas las organizaciones y partidos politicos derrotados en la guerra civil española, ejemplos que cuadrarían perfectamente en uno u otro supuesto. Pero es evidente, también, que debido al volumen de afiliación de la central anarcosindicalista durante la guerra, así como de la confianza que muchos de sus militantes inspiraban a los trabajadores, además de las supuestas «afinidades" expresadas más arriba, fue la Confederación el blanco de las miradas de los sectores falangistas del régimen.

En efecto, ya en el año 1935 se tiene constancia del interés del fundador de la Falange, José Antonio Primo de Rivera, en mantener contactos y unidad de actuación con la central anarcosindicalista. El líder falangista se dirigió a los sectores que mantenían una línea de actuación más posibilista, representada, en este momento, por Ángel Pestaña, líder «treintista» y fundador del Partido Sindicalista en 1934, quien, supuestamente, desvió las conversaciones hacia Abad de Santillán que decidió no aceptar el diálogo a pesar de que algunos compañeros de Centro y Andalucía creían que el entendimiento era posible ${ }^{6}$. Pero fue en la posguerra cuando los contactos entre falangistas y confederales tuvieron una importancia especial. En unos casos, con seguidores de José Antonio que no estaban conformes con las vias por las que circulaba la «revolución» prevista, e intentaron llegar a acuerdos con cenetistas para

Sobre estos contactos véase, ABAD dE SANTILLÁ, Diego, Memorias, Barcelona, Editorial Planeta, 1977, págs. 217/220. 
reconducir la situación ?. En otros casos, fueron falangistas inmersos en el régimen, quienes procuraron la captación de militantes libertarios que suplieran su inexperiencia en materia sindical, y que, al mismo tiempo, colaborasen en la desarticulación de la CNT clandestina mediante la infiltración, entre sus cuadros, de militantes "vendidos" al franquismo que delataron a buen número de compañeros.

La oposición a dicha colaboración tuvo un resultado trágico en los primeros años de la posguerra. Además de otros muchos militantes anarcosindicalistas que han permanecido en el anonimato, y que pagaron con la vida su negativa a participar activamente en el nuevo régimen, está el caso de Juan Peiró, antiguo ministro anarquista, que fue fusilado en Valencia, el 24 de julio de 1942, por negarse a colaborar en los sindicatos verticales. No faltan, en las memorias de los militantes anarcosindicalistas, los relatos sobre las ofertas y contactos con personas de la dictadura. Uno de estos encuentros tuvo como interlocutores a los cenetistas Enrique Marco Nadal y Lorenzo Íñigo, cuando ambos se encontraban en la cárcel cumpliendo condena, y fueron visitados por altos funcionarios del régimen franquista para cfrecerles su puesta en libertad y un marco legal especial para la CNT, además de las representaciones políticas y administrativas de la CNS a cambio de su colaboración en los sindicatos verticales. Ambos sindicalistas rechazaron la oferta, a pesar de que el primero tenía pena de muerte y el segundo una fuerte condena de cárcel sobre sus espaldas. Aunque, por ironías de la vida, la pena capital que tenía impuesta el primero, le fue conmutada gracias a la intervención de un antiguo militante cenetista que, en ese momento, ocupaba el cargo de Delegado de Información Social en el Ministerio de Trabajo $^{8}$.

Por el contrario, otros militantes aceptaron la colaboración. El ejemplo más significativo fue el que se dio en Całaluña, donde nada más finalizada la guerra civil se puso en marcha el Partido Sindicalista - que salvo el nombre nada tenía que ver con el creado por Ángel Pestaña-con Elíseo Melis ${ }^{9}$ a la cabeza, quien logró engañar a un buen número de militantes

7 Sheelagh Ellwood situó en 1945, la creación de una "Alianza Sindicalista", entre un grupo de falangistas, descontentos con la evolución del régirner, y anarcosindicalistas. Véase, ELLWOOD, S., Prietas las filas, Barcelona, Crítica, 1984, págs. 210-211

- Marco NadAl, E., Condenado a muerte, México, Editores Mexicano Unidos, S.A., 1966, págs. 56/59 y pág. 117. Proposiciones similares se pueden encontrar en el libro de Garcia DuRÁN, J., Por la libertad, como se lucha en España, México, 1956, pág. 161.

- Elíseo Melis fue uno de iantos militantes libertarios que terminada la guerra fue a parar a los calabozos de la policia en Cataluña. Se le dio a elegir entre trabajar para el franquismo o ser ejecutado; de esta forma pasó a ser un fiel colaborador de Quintela, jefe de Policía de la Brigada Social en Barcelona, y responsable de la detención de buen número de compañeros. El militante 
libertarios al proponerles la vuelta a la actividad netamente sindicalista de la CNT, con un alto grado de tolerancia por parte del régimen, y la "puesta en libertad" de algunos militantes encarcelados que, en más de una ocasión, actuaron como infiltrados de la policía. Con este doble juego, consiguió tener en sus manos, durante cierto tiempo, la organización clandestina de la CNT catalana, al ser elegido secretario general del comité regional a finales de 1942. Esta operación montada por el régimen, a principios de los 40, tuvo su continuidad en 1944 con la creación del Partido Laborista. En su formación colaboraron conocidos «treintistas" como Ricardo Fornells, Pedro Corrons o José Corbellá que, tras acuerdos con funcionarios franquistas, fueron liberados de los campos de concentración franceses y trasladados a España donde gozaron de cierta libertad para desarrollar su labor dentro de los sindicatos oficiales ${ }^{10}$. Con esta nueva operación, el régimen intentó, aparte de seguir construyendo su aparato sindical, dar una imagen de apertura en la sociedad española de cara a las potencias occidentales que, a estas alturas de la contienda, eran más que probables vencedoras de la 2. ${ }^{a}$ Guerra Mundial, con las consecuencias negativas que ello podría acarrear para el futuro del régimen.

El daño que, operaciones de este estilo, produjeron a la reorganización de la CNT, se puede apreciar en la propia Cataluña donde, en un informe de su comité regional, se llegó a pedir la ayuda necesaria a Francia para realizar una "acción violenta» contra los miembros de dicho partido, y en el que se reconocía que la organización estaba siendo minada "mediante el soborno y la promesa de ventajas" con las que algunos compañeros habían sido engañados y absorbidos ". Aunque el final "oficial» de Partido Laborista se sitúa sobre 1947 -momento en el que empieza a desaparecer la situación más delicada para el régimen franquista debido, en gran medida, al inicio de la Guerra Fría que fue determinante para su consolidación como consecuencia del apoyo que las potencias occidentales, encabezadas por Estados Unidos, le brindaron- todavía en los años

libertario José Pérez Pareja puso fin a los dias de Melis en julio de 1947. Pareja, que también murió en la acción, era miembro del Movimiento Libertario Anarquista, especie de rama militar del Movimiento Libertario Español.

10 Fornells y sus compañeros se dedicaron a reclutar militantes por los campos de concentración franceses para desplazarse a España y colaborar en esta empresa. Juan M. Molina cifra en unos trescientos los compañeros que aceptaron dicha proposición. Molina. J. M., op. cit., pág. 270. En referencia al apoyo y tolerancia del régimen hacia ellos, véase, MARCET Coll, J. M. ${ }^{\text {a }}, M i$ ciudady yo, Barcelona, 1963, pág. 122.

"El informe finaliza señalando que "La CNT expulsa inmediatamente a los compañeros que ingresan en el partido». Informe de la regional catalana, Archivo, Progreso Martínez, carpeta 39. Fundación Salvador Seguí, Madrid. 
cincuenta su sombra planeaba sobre la CNT, como se desprende de una circular que distribuyó el Sub Comité Nacional de Francia:

«EI CN informó a nuestro delegado sobre las actividades llevadas a cabo por el Partido Laborista, cuyos trabajos dirigidos por Girón, de acuerdo con Franco, tiende a ser una reserva que utilizará el régimen dictatorial como quiera y en el momento que juzgue oportuno. Los laboristas, si bien no están organizados legalmente en España, cuentan con la aquiescencia del régimen; se tolera su labor controlada; se explota el nombre de muchos de sus componentes para sembrar la confusión en las filas antifranquistas..." 12.

Al mismo tiempo, que estas operaciones tenían lugar, otros muchos militantes anarcosindicalistas, ya fuera individualmente o en pequeños grupos, empezaron a entrar en la organización vertical, principalmente desde 1947, a través de las elecciones sindicales que, desde 1944, convocó el régimen. El presentarse a ocupar los puestos de enlaces, en dichas elecciones, podía tener diferente motivación: algunos lo hicieron voluntariamente con la intención de proseguir su labor sindical e intervenir en la defensa de los intereses de los trabajadores; otros con la pretensión de mejorar su situación personal en los duros momentos de posguerra; los hubo que, como queda dicho más arriba, fueron "forzados" por sus compañeros que pretendieron tener una representación, más allá de las formalidades, para defenderse del patrón; $y$, en definitiva, aquellos que por sus conocimientos y el respeto del que eran depositarios, ya no sólo por parte de trabajadores sino también por los empresarios, fueron coaccionados por el régimen para incorporarse a la organización sindical franquista.

Un ejemplo muy significativo, en el que están reflejados muchos de estos supuestos, es el acontecido en Alcoy, Alicante. Alli, los componentes del Sindicato Textil de la CNT. en su mayoría "treintistas", llevaron a cabo la colectivización de la Industria del ramo durante la guerra civil. En el año 1939 fueron detenidos, juzgados y condenados a penas de cárcel, por su actividad en la contienda. Durante los años 45 y 46 , momento en el que comenzaron a ser puestos en libertad, no les daban trabajo, por su pasado "rojo", en las fábricas donde habían desempeñado su labor hasta el 36. En ese momento, fueron requeridos por lo dirigentes de la CNS para desempeñar cargos en el vertical. Según Celedonio Aparisi, hijo de uno de los fundadores de la colectivización, porque «los ideóiogos del régimen habían creado un sindicato y no sabian que hacer con él», y porque los militantes de CNT «eran muy conocidos y respetados tanto por la clase

12 Circular n." 21 del Sub CN de Francia, de fecina 7 de septiembre de 1955. Fondo, Ángel Marcos, sign., 114-1, Fundación Salvador Segui, Madrid. 
obrera como por la patronal» ${ }^{13}$. Algunos aceptaron como fueron los casos de: Vicente Oriola, Fernando Grau, Camilo Bito, José Sanus, Tomás Cantó, Juliá, Anselmo Sirera y Picó, muchos de ellos antiguos colectivistas; otros, como es el caso de José Aparisi, prefirieron quedar al margen. El cargo que desempeñaron en el Vertical fue el de Enlace Sindical, al que accedieron elegidos por los compañeros, y por el que no percibieron retribución alguna. Su ingreso en los sindicatos "oficiales" no significó el abandono de su actividad en la organización anarcosindicalista, y en el año 1947, diecisiete antiguos militantes cenetistas entre los que se encontraban, también, compañeros que no habian aceptado entrar a ocupar cargos en el vertical, fueron detenidos en Alcoy por recaudar dinero para ayudar a los compañeros que estaban en la cárcel, siendo juzgados por el cargo de reunión clandestina, por lo que fueron encarcelados por unos meses.

En Alcoy, la labor sindical cenetista en el vertical se extendió a lo largo de, prácticamente, todo el franquismo ${ }^{14}$, ya que estos militantes que desempeñaron cargos sindicales conminaron a otros compañeros e hijos de éstos para continuar su trabajo. Uno de estos casos es el de Celedonio Aparisi que, a petición de los antiguos colectivistas, ingresó en el vertical a principios de los cincuenta. Celedonio ocupó puestos de enlace y vocal social en el vertical; colaboró con grupos cristianos agrupados en la HOAC, con quienes presentó una candidatura conjunta para los cargos de las secciones sociales, y continuó desempeñando su trabajo sindical hasta el año 1969. Esta representación en el vertical no supuso ningún tipo de beneficio personal, y, por tanto, la vida de Celedonio, como la del resto de sus compañeros, fue la de un operario más, "trabajar doce horas diarias para poder mantener a la familia". Su relación con el resto de trabajadores era igual que la que habia imperado en la fábrica en épocas de la colectivización, y las charlas y reuniones de los trabajadores, tras su

${ }^{13}$ Carta de Celedonio Aparisi, Alcoy, 11 de abril de 2000. En el mismo sentido, Molinero e Ysàs, refiriéndose a las convocatorias electorales que se celebraron en los años 1947 y 1950 , después de constatar que dichas elecciones se desenvolvieron en un clima de escepticismo por parte de los trabajadores significan que también se eligió a muchos hombres y mujeres que tenian la confianza de sus compañeros: "Asi, en el textil, va a ser normal que antiguos afiliados de la CNT fueran elegidos enlaces y que actuasen dentro del sindicato". MOLInero C., e YSAS, P., Patria, jus ticia y pan, Magrana, Barcelona, 1985, págs. 45-46.

14 Igual sucedió en otros lugares de España; así en 1963, dos años antes del comienzo de las conversaciones cincopuntistas, en un informe policial, de julio de 1963, refiriéndose a la renovación de enlaces y jurados de empresa en las grandes empresas metalúrgicas de Barcelona, se puede leer: "siendo los nuevos componentes en muchos de estos centros (...) de tendencia marxista, cenetista y en menor número de la HOAC y falangistas". Molinero C, e Ysás, P., Productores disciplinados y minorias subversivas, Siglo XXI, Madrid, 1998, pág. 156. 
jornada, tenian lugar en el mismo sitio que se habian desarrollado en la época anterior a 1936, en un café de Alcoy llamado «El Trabajo». Celedonio rememora que aquellos que les «llamaron colaboracionista por estar en la CNS se dieron cuenta de que estábamos haciendo una buena labor entre los obreros". Hay que constatar que cuando, en el año 1976, se constituyó, en Alcoy, la Federación Local de Sindicatos Únicos de la CNT, Celedonio Aparisi fue elegido secretario general.

Como conclusión a este apartado, se puede asegurar que la inmensa mayoría de los militantes anarcosindicalistas se negaron a colaborar con el nuevo régimen. En el mismo sentido, la mayoría de los militantes cenetistas que entraron en el vertical, ya fuese voluntariamente $u$ obligados por el régimen o por los compañeros, lo hicieron con la idea primordial de proseguir su labor sindical en defensa de sus intereses de clase, y que, como en el caso de Alcoy, la ocupación de un cargo en el sindicato vertical no significó, para una amplia generalidad, ningún beneficio a título personal. En cuanto a la CNT, como organización, estuvo siempre en contra de cualquier tipo de "colaboración" con el franquismo. La central anarcosindicalista denunció todas esas maniobras orquestadas a gran escala desde la cúpula franquista, y no dejó de poner en aviso a sus militantes, a través de la prensa o de las circulares internas sobre la realidad que se encontraba detrás de las promesas de "vuelta al sindicalismo puro" y ulibertad de acción" que hacíarı sus exmilitantes, ahora colaboradores con el franquismo. Por otra parte, la CNT se mostró igual de intransigente con la participación de sus militantes en el sindicato vertical, y procedió a la expulsión de todos aquellos que ocuparon cargos en el mismo ${ }^{15}$.

\section{LAS NEGOCIACIONES CINCOPUNTISTAS}

La nueva situación creada en España, con la entrada de los ministros tecnócratas y el consiguiente cambio producido en la sociedad española, no pasó desapercibida para algunos militantes de la CNT, tanto del interior como del exilio, que empezaron a plantearse un cambio de estrategia a

15. En una circular, de abril de 1954, el comité nacional declaraba, 1." "Que existen acuerdos en el Pleno Nacional para no admitir ni tolerar la colaboración con el régimen franco-falangista en ningún sentido"; 2. Que la aceptación de cargos se consideraba colaboración con el franquismo, y por ello, "...Cuantos individuos hayan salido elegidos y hayan aceptado cargos, y que pertenezcan a la CNT, deben ser EXPULSADOS de la organización..."; 3. Que había que llevar un fichero verídico y lo más exacto posible de los militantes que colaboraban con el fascismo. Información que aparece en la circular $n . " 3$ del Sub Comité Nacional de Francia de fecha 6 de mayo de 1954. Fondo, Ángel Marcos, sign., 89-1, Fundación Saivador Seguí, Madrió. 
seguir para salir del inmovilismo al que, según ellos, había conducido el equipo directivo de la CNT en el exilio dirigido por Germinal Esgleas y Federica Montseny.

En efecto, en una carta, fechada en mayo de 1964, que los destacados militantes cenetistas en el exilio americano Pedro Herrera, Abad de Santillán y Manuel Villar enviaron a militantes del interior, en concreto a Madrid, se puede apreciar el embrión de lo que en un futuro, muy cercano, fue la base de las negociaciones con el vertical. Los militantes exiliados planteaban la necesidad de entrar en la CNS para, desde esta plataforma, contactar con los trabajadores, y, en consonancia con otras fuerzas democráticas antifranquistas, reivindicar mayor libertad de asociación e independencia sindical, derecho de huelga, atacar a la centralización y a la burocracia, y apoyar al movimiento cooperativo; puntos que, como se verá más adelante, quedaron recogidos en el futuro acuerdo cincopuntista. Además, este grupo de militantes hizo especial hincapié en la finalidad primordial de esta nueva estrategia, cuestión que, de haber sido respetada, hubiera podido significar un cambio de vital importancia para el desenlace ya no sólo del cincopuntismo sino, y quizá más importante, para el futuro de la CNT:

“...nuestra presencia en la CNS debe ser entendida a modo de una actividad de guerrillas.....guerra pública a los sindicatos verticales aunque se intervenga en ellos...lucha contra la dictadura hasta su destrucción..." ${ }^{16}$.

En enero de 1965, fue el Comité Regional de Madrid, en manos de Lorenzo Íñigo ${ }^{17}$ y Francisco Royano, quien sacó a la luz pública un documento titulado: "La CNT ante la realidad política española". En dicho comunicado, los firmantes, después de hacerse eco de la evolución socioeconómica que había experimentado la sociedad española, consideraban necesario superar la situación creada por la guerra civil española, y que tanto las derechas, con la Unión Nacional que pretendia la restauración de la Monarquía en la persona de D. Juan, como las izquierdas, con el PSOE a la cabeza, que seguía apostando por la República, estaban demostrando, anclados en este debate, su incapacidad para superar el estado de cosas actual. Como consecuencia de este análisis, la CNT, en

1. Carta de Pedro Herrera, Abad de Santillán y Manuel Villar, desde Buenos Aires, con fecha 30 de mayo de 1964. Archivo, Gómez Peláez, instituto internacional de Historia Social de Amsterdam.

17 Quien en octubre de 1962 había solicitado la baja de la CNT, y, sin embargo, volvió a aparecer al frente de la regional centro a finales de 1964. Véase. Damiano, C., La resistencia libertaria, Barcelona, Bruguera, 1978, págs. 290-294. 
opinión de estos militantes que creían en la evolución del régimen franquista hacia la democracia, debería rectificar su posición de aislamiento político, propiciar la desaparición de la política de dos bloques de la guerra civil y apoyar el restablecimiento de la democracia. La forma de gobierno sería decidida por las fuerzas políticas y sociales a posteriori. El presente documento tuvo una amplia difusión en las diferentes organizaciones regionales de la CNT, y una contestación especialmente crítica desde Cataluña, donde en esos momentos residia el Comité Nacional, con Cipriano Damiano como secretario general. Damiano apoyaba la Alianza Sindical Obrera, creada en 1962 y constituida a nivel nacional con la UGT, y que en Cataluña contaba con la participación de los cristianos de la SOCC. Esta nueva alianza reclamaba para el interior - aparte de cuestiones que, como el federalismo o la independencia de los partidos, no suponían ninguna controversia con la organización cenetista que se encontraba más allá de los Pirineos - la plena autonomía que le negaba el exilio y la futura unión sindical en una sola central, cuestión que era interpretada, por muchos militantes confederales en Francia, como el fin de la CNT. Por otro lado, la Alianza llevaba a cabo una serie de actuaciones que la enfrentaba radicalmente con las tácticas que proponía el exilio: participación en las elecciones sindicales, apertura hacia el obrerismo católico y, lo que era, todavía, más dificil de digerir, colaboración con los comunistas. Todas estas cuestiones hicieron que la militancia cenetista de fuera de nuestras fronteras se opusiera rotundamente a la ASO, y, en consecuencia, no reconociera al Comité Nacional representado por Damiano.

La organización de Madrid, inmersa ya en la preparación de las conversaciones con los dirigentes franquistas, y deseosa de hacerse con las riendas de la Confederación, tampoco apoyaba a la mencionada Alianza y propugnaba la celebración de un pleno nacional para imponer sus tesis en el conjunto de la organización. Este pleno nunca llegó a celebrarse durante el mandato de Damiano, en buena medida, por los continuos aplazamientos que este último propiciaba, consciente de la posición de inferioridad que su planteamiento, principalmente, en lo referente a la Alianza tenía, no sólo en el exilio o en Madrid sino en el resto de las regionales en donde la CNT tenía representación. La salida a esta situación vino como consecuencia de la detención del Comité Nacional de Damiano, en abril de 1965. El secretario general logró escapar y se refugió en Francia desde donde intentó seguir controlando la organización del interior ${ }^{18}$. Aprovechando la de-

18 Damiano, en sus memorias, deja entrever que la ola de represión que tuvo hugar en Cataluña fue propiciada por el grupo que estaba llevando a cabo las negociaciones, y que desembocaron en los cinco puntos. Damiano. C., La resistencia libertaria, Barcelona, Bruguera, 1978. 
saparición del anterior Comité Nacional, Francisco Royano, que era el delegado del mismo en Madrid, se hizo cargo de la secretaría general con carácter provisional, no sin una fuerte polémica con el titular anterior.

Mientras que todo esto sucedía, un grupo de militantes de la regional de Centro, compuesto por Natividad Adalia, Fulgencio Sañudo, Lorenzo Íñigo y el propio Francisco Royano, realizaban una serie de reuniones en las que analizaban la situación del movimiento libertario. Las conclusiones a las que se llegó, eran que la organización tenía que plantearse objetivos diferentes, más realistas y posibles. A estos antiguos militantes no se les escapaba, en su análisis, que la CNT era una organización que se encontraba en una situación deplorable por dos causas fundamentales: la represión franquista y la ausencia de jóvenes. La receta que se extendía para la mejoría del "paciente», tomaba como ejemplo la actuación de los comunistas a través de Comisiones Obreras, es decir: la penetración en los sindicatos verticales y, aprovechando la supuesta coraza que estos podían brindar, evitar las continuas represiones e ir captando a jóvenes, de entre los trabajadores, para asegurar, de este modo, el futuro de la CNT. Con estas premisas, estos cuatro militantes empezaron a tener contactos, en principio, con otros compañeros de la regional, y ampliaron el número de los asistentes a dichas reuniones con los compañeros Esteban Muñoz y Ángel Morales. Estos seis cenetistas, junto con compañeros de otras provincias, confeccionaron un escrito que vio la luz pública, en abril de 1965, y que, debido a la respuesta que tuvo por parte de personalidades franquistas, supuso un paso más en las conversaciones cincopuntistas.

El documento, en cuestión, se titula "Ante la problemática Sindical Española». Se partía de la necesidad de imprimir una evolución necesaria al régimen político, tanto por cuestiones naciones como internacionales. El mejor camino, para conseguir esta evolución, no era otro que la apertura al diálogo entre todos los sectores políticos y, principalmente, los sindicales, para alcanzar los siguientes objetivos: $10^{\circ}$ Sindicato único, libre y democrático; $2 .^{\circ}$ "control sindical de la propiedad social», y administración por los sindicatos de todas las propiedades de la actual organización sindical; $3 .^{\circ}$ "derecho de huelga", que quedaría limitada, únicamente, en los casos que perjudicase el interés general del país. Esta declaración pública tuvo una amplia difusión entre todos los sectores sindicales, y aunque no hubo respuesta oficial por parte de UGT ni de Comisiones Obreras, si la tuvo por parte de personalidades del régimen ${ }^{19}$.

19 No fue este el único documento que salió a la luz pública, en esta época, avalado por una fuerza sindical. Así, los dirigentes de Comisiones Obreras, en marzo de 1965, enviaron a altas je- 
En efecto, Adolfo Muñoz Alonso, catedrático de Historia de la Filosofía en la Universidad Complutense y director del Instituto de Estudios Sindicales, Sociales y Cooperativos, se puso en contacto con los firmantes del documento a través de Manuel Lizcano, que era ayudante de cátedra en la misma Universidad y director del departamento de Prospección Social en el instituto antes mencionado, y que, según ínigo, habia tenido contactos con los militantes cenetistas anteriormente, en la clandestinidad, cuando actuaba dentro de las Hermandades Obreras de Acción Católica. La primera reunión tuvo lugar entre Muñoz Alonso y Manuel Lizcano, por un lado, y Manuel Fernández, Francisco Royano y Lorenzo Íñigo por parte cenetista, quienes, según sus palabras, asistían a la reunión a título personal, sin ninguna representación orgánica de la CNT. Muñoz Alonso les planteó la posibilidad de iniciar un diálogo entre ambas partes, a lo que el grupo cenetista aplazó su contestación a la reunión que tuvo lugar en casa de Fulgencio Sañudo, y a la que acudieron, entre otros: Natividad Adalia, Francisco Royano, Monedero, Esteban Muñoz, Aquilino Padilla, Enrique Marco, Manuel Fernández, Gregorio Gallego, Eduardo de Guzmán, Lorenzo Íñigo, Luis Orobón Fernández y, el propio, Sañudo. Los asistentes analizaron, en profundidad, las consecuencias que pudieran tener el inicio de dichas conversaciones, y acordaron pedir opinión a los compañeros con los que se había contactado en las diferentes regiones ${ }^{20}$ que, en muchos casos, venían actuando, a "motu propio", dentro de los sindicatos oficiales. La respuesta fue positiva para el comienzo de las negociaciones.

El 25 de julio de 1965, a las diez de la mañana, en el Instituto de Estudios Sindicales se reunieron las dos delegaciones nombradas al efecto. Por un lado, aparte de Adolfo Muñoz Alonso y Manuel Lizcano Pellón, estaban: Antonio Chozas Bermúdez, Inspector General de la Organización Sindical; Francisco Lapiedra, Vicesecretario Nacional de Ordenación Social; Juan Ramón Ginestal, Secretario del Delegado Nacional de Sindicatos; José Lafont Oliveras, Presidente del Consejo Nacionai de Trabajadores; Dionisio Martín Sanz, Presidente del Consejo Nacional de Empresarios; Victor Arroyo Arroyo, Pre-

rarquías del franquismo un documento que, bajo el titulo: "Ante el futuro del sindicalismo", enumeraba las bases sobre las que debia regirse el futuro sindical del pais, y que guarda gran similitud con las propuestas cenetistas: diálogo entre los diferentes grupos sindicales, sindicato único regido por asambleas democráticas, derecho de huelga, derecho de asociación, independencia de los sindicatos en relación con los partidos... Fondo, Lorenzo İñigo, carpeta 54, Fundación Salvador Segui, Madrid.

20 En Barcelona: Julio del Alamo, Ladislao García, Sebastián Calvo y Antonio Gómez Nieto; en Bilbao: Juan María del Valle, Alejandro Fernández y Juan José Arrieta; en Alicante: José Espi Reig y Antonio Palacios; en Asturias: David Noval y Eiías Ortega; en Canarias: Julio Marrero Prieto; en Zaragoza: Evencio Garcia Monje y Felix Alferez; y en Valencia: Luis Silvestre y Octavio Alegre. Fondo, Lorenzo Iñigo, Fundación Salvador Seguí, Madrid. 
sidente del Sindicato Nacional del Combustible; Rodolfo Martín Villa, Presidente del Sindicato Nacional del Papel y Artes Gráficas; Alejandro Fernández Sordo, Presidente del Sindicato Nacional de Prensa, Radio y Publicidad; Antonio García Bernal, Presidente del Sindicato Nacional de Actividades Sanitarias; y Emilio Romero, Director del diario «Pueblo». La delegación cenetista estuvo compuesta por antiguos militantes anarcosindicalistas participantes en la guerra civil y, más tarde, en la lucha clandestina, lo que suponía muchos años de cárcel a sus espaldas y un pasado prestigioso en la CNT. Francisco Royano Fernández ${ }^{21}$, administrativo; José Espí Reig, zapatero; Enrique Marco Nadal ${ }^{22}$, ferroviario; José Marín Sánchez, empleado de comercio; Juan Ferrer Vilamala, empleado de hosteleria; Jaime Morancho Ponto, metalúrgico; Manuel Fernández Fernández ${ }^{23}$, practicante; Natividad Adalia ${ }^{24}$, ferroviario; Eduardo de Guzmán ${ }^{25}$, periodista; Gregorio Gallego Garcia ${ }^{26}$, pe-

21 Nacido en Andalucia se desplazó a Madrid a principios de la década de los 40, donde colaboró en la reorganización de la CNT. Formó parte de varios comités tanto regionales como nacionales, fue detenido, en marzo de 1945, cuando pertenecía al Comité Nacional del que era secretario general Sigfrido Catalá, pasó largos años en la cárcel.

22 Enrique Marco Nadal nació en el año 1914, ingresó en la CNT cuando contaba con 15 años de edad. Fue nombrado secretario general local a la edad de 18 años. Luchó en diferentes frentes durante la guerra civil, siendo hecho prisionero en el puerto de Alicante, y trasladado al campo de concentración de Albatera, del que salió con un aval falsificado. Pasó a Francia, y participó en la 2. a Guerra Mundial, siendo condecorado por los Estados de Francia y EEUU, y una vez licenciado se incorporó a la organización cenetista en Francia. Volvió a España, y ocupó el cargo de secretario general del Comité Nacional de la CNT. Fue detenido en Barcelona en mayo de 1947, y condenado a muerte; a los tres meses fue indultado; permaneció en prisión durante más de 17 años.

23 Militante gallego que fue el delegado de su regional en el primer Comité Nacional "orgánico" que tuvo la CNT en la clandestinidad, en julio de 1944. Perteneció a otros tres comités nacionales en los que la secretaria estuvo en manos de José Expósito Leiva, Ángel Morales y Lorenzo Ínigo. Fue detenido, perteneciendo a este último, en abril de 1946; pasó varios años en la cácel.

24 Compañero de Ángel Pestaña en el Partido Sindicalista, y al que sustituyó, tras su muerte, al frente de la secretaria del mismo.

25 Natural de Villada (Palencia), fue redactor jefe y director de varias publicaciones libertarias. Terminada la guerra fue detenido en el Puerto de Alicante; pasó por varios campos de concentración, y fue juzgado en un consejo de guerra en Madrid, en enero de 1940, que le impuso la pena de muerte. Fue indultado y excarcelado en diciembre de 1943. Colaboró en la reconstrucción de la CNT en Madrid, y perteneció al Comité Nacional clandestino de Manuel Amil, en marzo de 1944 Volvió a ser detenido, en junio de 1948, acusado de un delito de Rebelión Militar, del que fue absuelto. La represión franquista le impidió volver a desempeñar su profesión, teniendo que ganarse la vida como traductor o escritor, bajo seudónimo, de “novelas del oeste».

26 Nació en Madrid en julio de 1916. Ingresó en CNT y en Juventudes Libertarias en 1933; perteneció a la Junta de Defensa constituida en la capital. Como oficial del Ejército Popular luchó en diferentes frentes, y terminada la guerra pasó por diferentes campos de concentración y prisiones; fue puesto en libertad a finales de 1943. Ocupó el cargo de vicesecretario en el Comité Nacional clandestino de Manuel Amil en marzo de 1944. En enero de 1945 fue detenido en una redada cuando ostentaba el mismo puesto en el Comité Nacional de Sigfrido Catalá. Fue juzgado y condenado a 30 años de cárcel; permaneció más de 18 años en prisión. 
riodista; Luis Orobón Fernández, administrativo; y Lorenzo Íñigo Granizo ${ }^{27}$, empleado de Comercio.

La reunión tomó como base de discusión el documento presentado, en su momento, por los cenetistas. Desde el principio, los dirigentes franquistas pretendieron separar los posibles cambios que se pudieran llevar a efecto en materia sindical, de aquellos que tuvieran lugar en cuestión política. Además, el grupo que presidió Muñoz Alonso dejó claro que aunque, en un futuro, se podian abrir las presentes negociaciones a otras tendencias sindicalistas, en ese momento deberian ser, únicamente, los representantes cenetistas los interlocutores. Es necesario detenerse en estas dos importantes cuestiones ya que, su aceptación, suponía cambios apreciables con respecto a las posiciones que, a través de sus escritos, había defendido el grupo cenetista. Por un lado, no deja de asombrar que la delegación confederal aceptara la separación entre la democratización a nivel sindical de lo político o, cuanto menos, que no se plantease si los cambios que se pretendian en materia laboral eran posibles marginando la cuestión política. En cuanto a la condición de que fueran solos los cenetistas quienes participaran en las negociaciones con el vertical, era evidente que el seguir adelante, obviando dicha cuestión, en esas difíciles y controvertidas negociaciones, suponía correr un riesgo excesivo del que podía salir perjudicada la CNT, por mucho que se dijera que los allí presentes actuaban de forma privada. Además de estas premisas, en la misma reunión, Muñoz Alonso hizo lectura de un documento preparado por su delegación, titulado: «El asociacionismo sindical español»; que intentaba justificar la aparición de los sindicatos verticales para poner fin al enfrentamiento secular entre obreros y patronos. También queria demostrar la evolución democrática que, según ellos, había sufrido el sindicato desde 1942. Los verticalistas defendian la central única de afiliación automática, la creación de un Banco Sindical que se nutriria con las cotizaciones recaudadas de las asociaciones junto con la base patrimonial existente, y proponían la celebración de Congresos Sindicales como lugar de deliberación, compromiso y participación en la política, y en los Planes de

27 Ínigo nació el 10 de agosto de 1911, ingresó en la CNT en 1931 y en la FAl en 1932, siendo fundador de las Juventudes Libertarias en ese año. Fue secretario de la local de la FAl y del Comité Regional de las Juventudes Libertarias. Tras el Congreso de Zaragoza de 1936, fue miembro del Comité Nacional de la CNT. Durante la contienda nacional participó en la organización de la industria de guerra en Madrid, siendo nombrado posteriormente Consejero de Industria de Guerra de la Junta de Defensa. Terminada la guerra, fue hecho prisionero en el puerto de Alicante, y estuvc en prisión hasta marzo de 1945 Al salir fue elegido Secretario General del Comité Nacional. Fue deterido en abril de 1946, y condenado a 15 años de prisión. Salió en libertad condicional a finales de 1952 . 
Desarrollo. Por último, aceptaban el derecho de huelga, aunque se excluía la huelga política, y se defendía la independencia sindical, tanto respecto a las fuerzas políticas como al propio Estado.

A la delegación cenetista dicho informe les pareció "negativo y demagógico", por lo que la segunda reunión, que tuvo lugar el 27 de agosto, se saldó sin ningún avance en las negociaciones. Hubo que esperar al tercer encuentro que tuvo lugar el 4 de noviembre de 1965, en el mismo lugar y con los mismos interlocutores que participaron en las dos reuniones anteriores, para sacar adelante un documento conjunto. Los puntos de vista se habían acercado, y se propuso que dos de las personas presentes, una por cada delegación, redactaran un escrito que aunara las diferentes posiciones. Los verticalistas eligieron a Emilio Romero, que aceptó el nombramiento; por parte cenetista, fue propuesto Eduardo de Guzmán, quien rehusó, y propuso a Lorenzo Íñigo; proposición que fue aceptada por los confederales. El documento redactado se tituló: "Acuerdos provisionales entre militantes del sindicalismo oficial y militantes del sindicalismo libertario, encaminados al desarrollo y perfección del sindicalismo obrero español». El acuerdo se puede sintetizar en cinco puntos: $1 .{ }^{\circ}$ Sindicato único, con afiliación automática en cuanto se ejerciera cualquier actividad laboral; 2. Autogobierno de los trabajadores en su organización, independencia sindical respecto al Estado y organizaciones políticas, y separación de las organizaciones empresariales; $3 .^{\circ}$ Mutualismo laboral, así como la participación de los sindicatos en la planificación y ejecución de la política de desarrollo a cualquier ámbito estatal; $4 .^{\circ}$ Se reconocía el derecho de huelga, considerándose lícitas, solamente, aquellas que fueran convocadas por las organizaciones sindicales obreras; $5 .^{\circ}$ Desarrollo del cooperativismo. A estos puntos se añadió un acuerdo adicional, a propuesta de ínigo, según el cual, el presente documento se trasladaría a UGT, CCOO, Demócratas Cristianos y, a la propia, CNT, invitándoles a adherirse. Se estableció un plazo de treinta dias para conocer las respuestas, encargándose la parte libertaria de llevar a cabo estas gestiones. Este documento fue aprobado por las dos delegaciones, aunque no firmado, porque tanto unos como otros decian no ostentar ningún tipo de representación oficial de sus respectivas organizaciones.

Las criticas que se pueden verter, y de hecho se vertieron, sobre el pacto cincopuntista son, en general, bastante negativas: por un lado, en cuanto a las formas, al entender que nunca ningún militante confederal se tenía que haber sentado a negociar con representantes franquistas, con los mismos que acababan de celebrar sus " 25 años de paz" labrada a base de llenar prisiones y cementerios; por otra parte, en el fondo: en primer lugar, por no considerar como una cuestión previa, pero fundamental, 
para el inicio de las negociaciones, el fin de la represión y la consiguiente amnistia, de la que se deberían de haber beneficiado todos los luchadores antifranquistas; en segundo lugar, porque no se cuestionaba la propia existencia del sindicato vertical, es más se hablaba de la cotización obligatoria de los trabajadores, obviando el derecho de éstos a elegir su sindicación, lo que podia entenderse como la continuidad del sindicato existente; en tercer lugar, porque los cinco puntos recogían todas las cuestiones que habían presentado los franquistas, y, exceptuando el derecho de huelga, los acuerdos no aportaban nada especial a las actuaciones que el sindicato vertical tenía previsto desarrollar en un futuro cercano a través de sus famosos Congresos Sindicales; $y$, en definitiva, porque la única negociación posible era la que significara el cambio del régimen dictatorial por uno democrático a todos los niveles, y no, como emanaba del acuerdo, sólo en la parcela sindical.

Sin embargo, desde otro prisma, el que tenían los negociadores confederales, era necesario acercarse a la realidad de la organización cenetista en el interior en ese momento, y desde esa realidad conocer las motivaciones y fines que impulsaron a estos dirigentes a dar un paso tan arriesgado. Los años de represión franquista habian dado sus frutos, y el miedo a la detención, tortura y vuelta a la cárcel suponian el principal escollo para la continuación de la labor orgánica en una militancia envejecida. En otras organizaciones, como la comunista, muchos de sus militantes no habian participado en la guerra civil, y, por consiguiente, no habían soportado largos años de cárcel en el momento más duro de la dictadura. En la organización confederal no se había producido el relevo generacional tan necesario, y la vieja militancia no estaba dispuesta a seguir luchando con la perspectiva de una nueva represión. Con estas premisas, la nueva dirección de la Confederación entendía que el único camino viable, con vistas al futuro, era el que asegurara la actividad sindical sin el riesgo de la represión, cuestión que, según ellos, sólo era posible mediante un pacto con los verticalistas, y la incorporación a los sindicatos oficiales. Su finalidad, para con el vertical, consistía en intentar su democratización; y, para con la CNT, encontrar entre la masa de trabajadores esos jóvenes a quienes, a través de los cursos que organizase el sindicalismo oficial, se los formara en la ideología libertaria.

Poi su parte, los negociadores que representaban a la organización sindical franquista tenían la necesidad de un cierto reconocimiento internacional que les permitiera recuperar posiciones en el interior, como queda dicho más arriba, en su lucha por el poder contra "ultras" y «tecnócratas»; asi como mejorar la imagen exterior del régimen, al tiempo que legitimarse, a través de incorporar en sus instituciones a algún grupo de la oposi- 
ción. En palabras del entonces delegado provincial de sindicatos de Barcelona, Rodolfo Martín Villa:

"La Organización Sindical tenía la necesidad de engullir a algún sector de la oposición obrera” ${ }^{28}$.

Cada grupo, desde este momento, se puso a trabajar para poner en práctica los acuerdos alcanzados. Los libertarios, en primer lugar, pidieron su colaboración a un grupo de destacados militantes que se encontraban en el exilio como eran: Horacio M. Prieto, Juan López y Diego Abad de Santillán. El primero de ellos - que fue secretario general de la CNT en 1936 y, para muchos, principal artífice de la colaboración ministerial de la CNT durante la guerra civil española- negó su colaboración. Horacio había evolucionado en su pensamiento, para él la cuestión sindical ocupaba, en esos momentos, una posición secundaria, en detrimento de la cuestión política, con una revalorización del papel del Estado. Además, dudaba de la posible democratización del régimen, al tiempo que persistía en su idea de formar el Partido Libertario ${ }^{29}$. Los otros dos estuvieron a favor de las negociaciones, Abad de Santillán - que fue miembro del Comité Peninsular de la FAl, perteneció al Consejo de Economía de Cataluña en el que desempeñó el cargo de delegado de Combustibles y Fuentes de energía, y en diciembre de 1936 fue designado titular de la cartera de economía del Gobierno de la Generalidad de Cataluña- mostró su apoyo desde el exilio americano; y Juan López, el que fuera ministro en el gobierno de Largo Caballero junto con Federica Montseny, Juan Peiró y García Oliver, regresó a España y se puso al frente de la cooperativa de los Transportes Urbanos de Valencia (SALTUV). Por otro lado, en cumplimiento de lo acordado, los libertarios pusieron en conocimiento de la Unión General de Trabajadores, la Federación Sindical de Trabajadores y Hermandades Obreras de Acción Católica los acuerdos alcanzados invitándolos a participar en su rúbrica definitiva. En general, salvo raras excepciones ${ }^{30}$, la posición de las organizaciones antifranquista fue de com-

28 Testimonio recogido en MAteos, A., La denuncia del sindicato de vertical, Madrid, Consejo Económico y Social, 1997, pág. 94.

29 Carta de Horacio M. Prieto a Lorenzo Ínigo, de fecha 8 de septiembre de 1965. Fondo, Martinez, carpeta 170. Fundación Salvador Seguí. Madrid.

30 Como las que representaron: Alfonso Fernández Torres, dirigente sevillano de la UGT con apoyos en Andalucía, Levante y Madrid; asi como un sector de los cristianos de la FST, o el propio Tierno Galván que apostaba por aprovechar cualquier resquicio de apertura que dejara el régimen. Véase, Mateos, Abdón, El PSOE contra Franco, Madrid, Fundación Pablo Iglesias, pág. 377. Lorenzo Íñigo señala que algunos veteranos ugetistas madrileños, como Gómez Egido, habían manifestado la conveniencia de entrevistarse con los cenetistas para conocer todos los en- 
pleto rechazo tanto a las negociaciones, como a los acuerdos consiguientes. Los cenetistas solamente recibieron contestación por parte del sindicato socialista que desde su Comisión Ejecutiva, con sede en Toulouse, rechazaron la invitación de incorporarse a la mesa negociadora. El resto de organizaciones ni siquiera contestó. La actitud de la Organización Internacional del Trabajo, o de la Federación Internacional Metalúrgica, junto a los sindicatos anglo-norteamericanos fue menos radical, y creyeron ver, en los acuerdos, un cambio de actitud en la dictadura franquista ${ }^{31}$. Por último, los negociadores cincopuntistas buscaron la "legitimidad" a su representación y la ratificación de los acuerdos alcanzados, como veremos más adelante, a través de un pleno nacional de regionales.

Los franquistas, por su parte, procedieron a la difusión del documento cincopuntista en el seno del Sindicato Vertical. Pero si, como hemos visto, los confederales tuvieron en contra a todas las organizaciones antifranquistas que habían mostrado su enérgico rechazo al pacto, los falangistas tuvieron que hacer frente a la oposición que, desde dentro del régimen, representaban los "ultras" y los "tecnócratas" del Opus Dei; los primeros, por considerar inconcebible cualquier contacto con el enemigo; los segundos, porque entendieron las negociaciones abiertas con los libertarios como un ataque frontal contra su reciente hegemonia en el poder.

Duranie el mes de abril de 1966, las negociaciones se hicieron públicas; primero, por las denuncias que, en una rueda de prensa clandestina ante corresponsales extranjeros, celebró en Madrid, el 6 del mismo mes, Luis Andrés Edo, militante de la Federación Local de París; y, seguidamente, a través de diferentes informaciones en la prensa nacional ${ }^{32}$. El revuelo originado llevó a tratar el tema en el Consejo de Ministros del 6 de

tresijos de la negociación, proposición que no fue escuchada. Fondo, Lorenzo Ínigo. Fundación Salvador Seguí, Madrid

31 Mateos, A., La denuncia del sindicato vertical, Madrid, Consejo Económico y Social, 1997.

32 Las intormaciones sobre las negociaciones aparecieron en la piensa nacional, principalmente, en los dias 22 y 23 de abril, aunque se alargaron en los meses sucesivos. Cada diario apoyaba o vilipendiaba las negociaciones en relación con su posición dentro del régimen. Así, el diario "Ya", en su edición del 4 de mayo de 1966, identificaba las negociaciones con signos de reconciliación: “...porque los resentimientos que florecieron tristemente en el pasado aparecían espectacularmente atenuados o desaparecidos", y de apertura, ya que la Organización Sindical quiere "proseguir su proceso de integración de todos...de consolidar un sindicalismo que ha sido ya elevado a la dignidad de representación pública". Sin embargo, estos planteamientos contrastaban con los del diario "Informaciones", que fueron recogidos, también, por "Ya" el 6 de mayo: «Porque nosotros, como un enorme sector del país. no podemos asimilar ese concepto que algunos tienen de la CNT como entidad ingenua, benéfica y pastoril que no desea más que el bienestar del género humano, bienestar que es generosa en proporcionar por los procedimientos más convincentes, entre los que se encuentra el rapto o el paseo por una hermosa carretera, como la de Barajas". 
mayo. Solís insistió en la necesidad de incorporar a parte de la oposición a la organización sindical. Franco zanjó la cuestión ordenando el fin inmediato de las conversaciones ${ }^{33}$. Normalmente este momento ha sido considerado como el fin de lo que se ha venido llamando "cincopuntismo". Pero, en lo que se refiere a la vida interna de la CNT, nada más lejos de la realidad; lo cierto es que las negociaciones, y sus inevitables repercusiones, siguieron haciendo acto de presencia, tanto en el interior, donde el grupo que inició las conversaciones perseveró en sus intenciones; como en el exilio, cuyos militantes también se vieron sacudidos fuertemente por las negociaciones. Las secuelas continuaron hasta bien entrada la etapa democrática en nuestro país.

\section{EVOLUCIÓN DEL CINCOPUNTISMO EN EL INTERIOR}

Es necesario decir, como primer punto a tener en cuenta, que las negociaciones cincopuntistas contaron con el rechazo de la inmensa mayoría de los militantes cenetistas En el momento de hacerse públicas las conversaciones, hubo una reacción contundente por parte de la militancia cenetistas llegando a aparecer varios comunicados de supuestos "comités nacionales» negando validez a las conversaciones. Pedro Barrio militante que colaboró en la reorganización de CNT en los años 40 , y que formó parte del Comité Nacional en 1976, cuenta como

"El grupo Anselmo Lorenzo (formado por militantes apartados de la actividad orgánica pero que mantenía reuniones y contactos con otros compañeros) dijimos: "para un cuarto de hora nos vamos a hacer comité nacional", e hicimos un manifiesto como comité nacional, que ni era comité nacional ni nada, era el grupo Anselmo Lorenzo, en el manifiesto nos oponíamos a que se pactara con los falangistas, desautorizándoles...este manifiesto lo mandamos a Falange, a los sindicatos, a los gobiernos civiles... igual que nosotros aparecieron cinco o seis comités nacionales más" ${ }^{34}$.

Pero, una vez constatada esta fuerte oposición, no es menos cierto que muchos de estos militantes se encontraban completamente apartados de la organización cenetista, viviendo, después de largos años de cárcel, su "exilio interior». El resto de compañeros que trabajaban en la organización clandestina eran, a mediados de los sesenta, pequeños grupos

33 Véase, Mateos, Abdón, La denuncia del sindicato vertical, Madrid, Consejo Económico y Social, 1997, pág. 98.

34 Entrevista a Pedro Barrio en Madrid el 27 de abril de 1999. 
en diferentes regiones, lejos de abarcar toda la geografía española, y que en la mayoría de los casos no tenían contactos entre sí o que si los había eran tan débiles que quedaban rotos con cierta facilidad, además su actividad era muy reducida ${ }^{35}$. Por otro lado, había militantes que, como queda reflejado más arriba, estaban trabajando en la organización vertical, pero su actividad era individual sin ninguna coordinación entre ellos, y sin el apoyo de la organización, es más, muchas veces con el repudio de ésta y de sus antiguos compañeros. Para la implantación cenetista en los sindicatos verticales, el grupo que dirigían Íñigo y Royano intentó aprovechar el trabajo realizado por estos militantes que desde hacía muchos años estaban trabajando dentro de la CNS, con la idea de coordinar y sacar provecho orgánico a toda esa actividad. Por su parte, estos militantes vieron en los cinco puntos la posibilidad de articular su labor a nivel nacional con otros compañeros que, desde hacía años, la realizaban de forma aislada. La CNT inauguraba, de esta forma, una situación que supuso una nueva reorganización, con su implantación en un buen número de regiones, coordinación de la actividad de sus militantes en el interior y que, de haber sido bien encauzada, hubiera supuesto un desenlace muy diferente del actual para la organización anarcosindicalista ${ }^{36}$.

En efecto, durante los meses de septiembre y octubre de 1965, los dirigentes madrileños comenzaron la visita a diferentes regiones para reorganizar los cuadros confederales de la CNT bajo la base de la penetración en los verticales. Se creó la Comisión Nacional de Coordinación Confederal compuesta por Francisco Royano, Natividad Adalia y Lorenzo Íñigo; y se organizaron las diferentes Comisiones Regionales que estuvieron formadas, en el Centro por: Esteban Muñoz, Fulgencio Sañudo y Rafael Rosillo; en Cataluña: Juan Ferrer, Sebastián Calvo y Antonio Turón; en Levante: Sebastián Martínez, Octavio Alegre y Antonio Quinto; en Aragón: Francisco Leal, Evencio García y J. José Izquierdo; en Andalucía: José

35 Honorato Martínez que perteneció al Comité Nacional de la CNT, cuyo secretario general fue Ismael Rodríguez en el otoño de 1950, cifra la cantidad de militantes en este momento de 500 para toda España. Sobre la poca actividad de la organización, señala que cuando detuvieron a este Comité "no llegaron a juzgarles...saiieron al año siguiente en libertad... no les juzgaron porque no encontraron nada para condenarles, sólo eso que pertenecian a un comité pasivo". Con la detención de sus compañeros quedó interrumpida la comunicación entre las regionales por largo tiempo. Entrevista a Honorato Martínez Fuster en Madrid el 1.3 de enero de 2000.

36 Celedonio Aparisi comenta que la CNT en Alcoy, como organización, había desaparecido a finales de los cuarenta, y que no volvió a estar estructurada y en contacto con otros lugares de Es. paña hasta 1965. Entrevista a Celedonio Aparisi, en Alcoy el 3 de junio de 2000. En Badalona, Costa, que era otro de los cenetistas que ya, en ese momento, era enlace sindical, señala que logró agrupar a muchos compañeros tras la idea de los cinco puntos. Carta de Costa Font a la Fundación Salvador Segui en noviembre de 1988. Sin clasificar, Fundación Salvador Seguí, Madrid. 
Marin, M. Ramírez Castillo y J. Romero; en Galicia: Nicolás Mayo, A. Fandiño y M. Vázquez San Payo; en Extremadura: J. Fernández y Antonio Luengo; en Asturias: David Noval y Nicolás Muñiz; y en Canarias: Nicolás Padrón y Julio Marrero. Además se constituyeron delegaciones en Francia, Inglaterra, México, Caracas y Argentina. Una vez que se llegó al acuerdo del 4 de noviembre, la situación pareció cambiar para la CNT que, ahora con el "paraguas antirrepresivo" que brindaba la negociación con los verticales, logró reunir, según Lorenzo Íñigo, a 400 militantes en una asamblea que se celebró en el salón de actos de la Escuela de Formación Profesional de la Paloma, en Madrid. Los asistentes aprobaron la gestión realizada por los compañeros, quienes, de todas formas, necesitaban el refrendo de toda la organización para seguir adelante sus negociaciones, ahora ya de una forma oficial, con los representantes franquistas, y que consiguieron en el Pleno Nacional de Regionales que se celebró en Madrid, el 5 de diciembre de 1965.

En dicho Pleno estuvieron representadas las regionales de Cataluña, Levante, Centro, Andalucia, Norte, Asturias, y Galicia ${ }^{37}$. Presidió el comicio: Francisco Royano, en su calidad de secretario interino de la organización. Dos fueron las cuestiones principales que tuvo que abordar el Pleno: en primer lugar, otorgar la representatividad de la CNT a los dirigentes que habian llevado a cabo la negociación; en segundo lugar, la aprobación de dicha gestión por la organización y trazar el camino a seguir tomando como base los cinco puntos. Royano leyó el informe del Comité Nacional, según el cual, tras la huida de Damiano a Francia, la delegación del Comité Nacional en Madrid, de acuerdo con el Comité Regional de Centro, asumió las funciones de Comité Nacional. El secretario interino criticó duramente la actitud de Damiano al nombrar a un compañero, por su cuenta, para que le supliera al frente de la secretaría, y, mientras tanto, pretender controlar la organización desde Francia con el envío de comunicados y cartas que siguió firmando como secretario del Comité Nacional de España. Royano hizo especial hincapié en la vinculación de Damiano con la Alianza Sindical Obrera, de la que decía que jamás había sido aprobada por la organización en reunión del Comité Nacional, ni por ninguna regional excepto Cataluña. El Pleno consideró la gestión de Damiano carente de sentido y de responsabilidad orgánica, y respaldó la actuación

37 En el informe, que sobre la situación orgánica presentaron las Regionales, se demuestra, una vez más, el grado de falta de organización de la CNT con anterioridad a las negociaciones cincopuntistas. La mayoría de las regionales sitúan a finales de 1960, cuando era secretario general Ismael Rodriguez, el último contacio con el comité nacional. Fondo, Antonio Barranco, carpeta 98 , Fundación Salvador Segui, Madrid. 
de la delegación del Comité Nacional en Madrid. En definitiva, el Pleno reconoció como legítimo al Comité presente, y, por lo tanto, desautorizó al anterior Secretario General y a los que con él colaboraron.

Sobre la aprobación de la gestión realizada, el debate contó, desde el principic, con la oposición de la delegación de Asturias, en la que se encontraba Ramón Álvarez, que había venido desde París clandestinamente para asistir al comicio. Para los asturianos, después de advertir que no ponían en duda "la horiestidad de ningún militante ni queremos comprometer la estructura orgánica en el interior", se había ido demasiado lejos en las negociaciones; la delegación Asturiana puso el acento en la política de hechos consumados llevada a cabo por la delegación de Madrid, aunque en este caso fuera "un escrito sin firmas"; por otro lado, no creía en las democratización del régimen, y consideró un riesgo excesivo el que la CNT asumiera individualmente el peso de la negociación; en definitiva, según su criterio, la situación había requerido una consulta más amplia con maj'or participación del exilio, así como la realización de un pleno con mayor representatividad ${ }^{38}$. Royano informó que toda la organización, tanto del exilio como del interior, habia sido invitada, y sólo habian hecho acto de presencia los allí reunidos. Royano preguntó al Pleno, si éste consideraba que tenía la soberanía suficiente, y si todas las delegaciones presentes acatarian lo que decidiera la mayoria. A ambas preguntas la contestación fue afirmativa. En suma, la gestión del nuevo Comité fue aprobada con el voto a favor de todas las delegaciones, excepto Asturias.

Antes de la elección de los cargos del secretariado, una cuestión, cuya importancia se fue acrecentando con el paso del tiempo, fue motivo de discusión por parte del Pleno, me estoy refiriendo a la existencia o no de la CNT en el futuro. A ninguno de los presentes se les escapó que uno de los cinco puntos, concretamente el que se refiere a la sindicación única, podía significar la desaparición orgánica de la Confederación, por lo que se planteó la necesidad de encontrar una nueva forma asociativa de los cuadros confederales. Centro, regional a la que, como se sabe, pertenecian la mayoría del primer núcleo negociador, propuso, para su discusión en las regionales, la creación de una nueva organización específica que agrupara a los confederales españoles y coordinase la acción individual de los libertarios en el nuevo sindicato. La delegación de Centro hasta tenía pensado el nombre: Federación Sindicalista Libertaria, que tendría como sistema orgánico las agrupaciones locales, federadas nacionalmente a todos los niveles: comarcal, provincial y regional, e integradas en una $\mathrm{Fe}$ -

38 Fondo, Antcnio Barranco, carpeta 98, Fundación Salvador Seguí, Madrid. 
deración Nacional. El Pleno aprobó, como tal sugerencia, su discusión. Por último, el Pleno nombró al nuevo Comité Nacional. Francisco Royano fue elegido secretario general; Lorenzo Íñigo, secretario de organización y Aquilino Padilla, secretario de propaganda.

En definitiva, el Pleno supuso un gran éxito para los militantes que habian llevado a cabo las negociaciones, principalmente para Royano $\mathrm{e}$ Ínigo, ya que consiguieron sus dos objetivos principales: la aprobación de las gestiones realizadas y hacerse cargo de la representación de la CNT; en cuyo nombre, ahora si, pudieron seguir la negociación, con el gran salto cualitativo que ello significó, al pasar de ser consideradas unas conversaciones personales a tener el marchamo de oficiales. Pero, desgraciadamente para el futuro de la CNT, el nuevo grupo dirigente del interior comenzó una carrera alocada en la que se fueron quemando etapas rápidamente sin que, por otro lado, se corroborasen las premisas fundamentales planteadas, entre ellas: la supuesta evolución democrática del régimen, sobre las que estaban asentadas las negociaciones. Desde este momento, la CNT, a diferencia de la actuación que estaban lievando a cabo los comunistas en Comisiones Obreras, fueron dejando de lado su actuación clandestina en beneficio de la oficial que desarrollaban en los sindicatos verticales. Una vez más, la CNT hizo gala de una falta de flexibilidad secular en el desarrollo de sus principios y tácticas, y la dirección planteó su actuación en términos maximalistas, o trabajo en el vertical o clandestinidad, cuando la opción verdaderamente acertada, como se estaba demostrando, era la coordinación de ambas tácticas. Todo esto, claro está, teniendo en cuenta que, en realidad, la actuación de los nuevos dirigentes cenetistas estuviera encaminada a la destrucción de los sindicatos verticales o cuanto menos a su democratización, y no hacía su conservación con la única idea de apoderarse o quizá, como les acusaban sus antiguos compañeros, de instalarse en ellos, como parecía indicar la línea que, desde ese momento, siguió el nuevo secretariado. Por ello, cuando en abril de 1966, como hemos visto, fueron hechas públicas las negociaciones, con el consiguiente punto final a las mismas, la CNT no cambió su estrategia.

En efecto, la ocupación de cargos sindicales en las elecciones que se celebraron a finales de 1966, fue el objetivo prioritario de la dirección cenetista. La presencia de militantes libertarios en puestos sindicales se consideró como el primer eslabón necesario para la puesta en práctica de los cinco puntos pactados con los verticalistas. Para ello se constituyó una comisión nacional y varias comisiones provinciales, que coordinaron la actuación de los militantes cenetistas que concurrieron, en dichas elecciones, junto con algunos "asoistas»; ya que con anterioridad, en julio de 1966, el 
Comité Nacional de la CNT, con Royano e Íñigo, llegaron a una acuerdo con un sector socialista inscrito en la Alianza Sindical Obrera para establecer secciones coordinadas para las próximas elecciones sindicales, respaldando los cinco puntos aprobados en noviembre de 1965. Esta iniciativa significó, prácticamente, el fin de dicha Alianza, ya que supuso su abandono por parte de la UGT de Cataluña y otros grupos neosocialistas. En la Comisión Central Nacional estuvieron presentes: Lorenzo Ínigo Granizo, Francisco Royano Fernández, Enrique Marco Nadal, Josefina Arrillaga Lansorena, José Suarez Carreño y Bernardo Ruiz - estos tres últimos pertenecientes a ASO-; en la Comisión Provincial de Madrid: Cecilio Rodríguez Garcia, Rafael Rosillo Bermúdez, Jesús González Quesada y Manuel Macias; en Barcelona: Juan Ferrer Villamala, Sebastián Calvo Sahún, Antonio Turón, Ladislao García Fontana y Edmundo Valles Berdrix; en Valencia: Antonio Quinto Seguí y Sebastián Martínez Serrano; en Murcia: José Cortés López y Francisco Liza; en Sevilla: José Romero González y Manuel Ramírez Castillo; en Zaragoza: Juan José Izquierdo y Antonio MaIlallo; en la Coruña: Alfonso Fandiño Ricart y Manuel Vázquez Sampayo; y en Alicante: Vicente Lillo y José Espi Reig ${ }^{39}$.

A pesar de todo, el resultado de estas elecciones sindicales no fue nada halagüeño, es más se constató un retroceso cenetistas en relación con anteriores convocatorias electorales y un avance de Comisiones Obreras. Así se desprende de un informe policial sobre los representantes obreros elegidos como Jurados y Enlaces de las principales empresas del sindicato del metal, que señalaba

"un predominio de las Comisiones Obreras, e incluso de los comunistas.... (y que) las impresiones que tienen los dos anteriores grupos que hasta ahora han dominado este Sindicato, la mayoritaria o cenetista (formada por antiguos afiliados a la CNT pasados al verticalismo) (...) y la minoritaria en la que hay algunos elementos falangistas, en ambos grupos, son de desmoralización $\gg{ }^{40}$.

A pesar de que el resultado obtenido no fue el esperado, la CNT siguió adelante, en su nueva andadura, en dos direcciones: una, próxima en el tiempo, insistiendo en los cinco puntos para su inclusión en la nueva ley sindical, para lo cual, por un lado, perseveraron en las conversaciones con los dirigentes franquistas como se desprende de las actas de los dife-

\footnotetext{
Fondo, Lorenzo Íñigo, carpeta 55, Fundación Salvador Segui, Madrid.

40 Nota informativa de fecha 4 de octubre de 1966. Véase, MOLINERO, C. e Ysás, P., Productores disciplinados y minorías subversivas, Madrid, Siglo XXI, 1998, pág. 161.
} 
rentes plenos y reuniones ${ }^{41}$; y por otro, a través de las ponencias que los representantes cenetistas intentaron imponer en los congresos sindicales que organizó el sindicato vertical ${ }^{42}$. Con relación a la otra actuación, que se presumía de largo recorrido, el secretariado de la CNT intentó, con vistas al futuro, aprovechar las posibilidades que le ofrecía su participación en el vertical, utilizando sus instalaciones y los cursos de formación sindical, para suplir una de sus deficiencias más importantes: la inexistencia de jóvenes trabajadores en sus filas. La CNT planificó el nombramiento de los Delegados de Barriada, que tendrian su actividad, de acuerdo con la Junta de Orientación Sindical, en los centros donde se organizarían charlas, conferencias, clubes deportivos, etc. Se constituirian los grupos de Orientación Sindical, tomando como base los enlaces en las empresas para, desde aquí, ir captando jóvenes. Al mismo tiempo, se intentaría introducir, en los cursos de Capacitación Sindical, un plantel de profesores para que orientasen, de una forma libertaria, a los futuros representantes de los trabajadores ${ }^{43}$. Luego la realidad fue diferente, ya que no se pudo crear los Grupos de Orientación Sindical por la oposición de los jerarcas sindicales. Solamente se pudo establecer unos seminarios para apertura informativa y de formación a través del Instituto de Estudios Sociales, Sindicales y Cooperativos.

Pero el intento de realización de todos estos planteamientos llevó implícito un cambio de rumbo en la táctica que el grupo dirigente de la CNT, en concordancia con las regionales, había trazado hasta el momento. Lorenzo Íñigo y Francisco Royano - desde hacía tiempo abandonados por la inmensa mayoría de los compañeros que formaron el primer núcleo de las conversaciones cincopuntistas - fueron, poco a poco, absorbidos por la burocracia sindical, y terminaron defendiendo posiciones muy alejadas, ya no sólo, de las aceptadas al inicio de las conversaciones, cuando se quería la modificación democrática de los sindicatos, sino también de los compañeros confederales que les apoyaron tanto en las regionales del interior como en el exilio, y que, con la evolución de los acontecimientos, vieron

41 El secretario de la Regional de Levante informó, en la plenaria de esta regional, a principios de 1968, de las negociaciones que seguian teniendo lugar en Madrid con los representantes de los sindicatos oficiales; incluso habló de una entrevista entre el Delegado Nacional de Sindicatos y Ministro Secretario del Movimiento, con el Vicepresidente del Gobierno, Carrero Blanco, que estuvieron cambiando impresiones sobre el espiritu de los cinco puntos. Archivo personal de Celedonio Aparisi.

42 Esta estrategia se puede apreciar en las Actas del Pleno de militantes de Madrid de fecha 19 de febrero de 1967. Fondo, Lorenzo Îñigo, carpeta 55, Fundación Salvador Segui, Madrid.

43 Actas del Pleno de Militantes de Madrid, celebrado en el Colegio de la Paloma, el 19 de febrero de 1967. Fondo. Lorenzo ínigo, carpeta 55, Fundación Salvador Seguí, Madrid. 
como una posibilidad real la desaparición de la CNT en beneficio de la continuidad del aparato sindical franquista.

Efectivamente, si en un principio se cometió el error, como hemos visto, de entender las negociaciones descle una perspectiva puramente sindical sin incluir la necesidad de un cambio en el sistema político, esta tendencia se fue acentuando hasta llegar a pedir a los militantes confederales ya no sólo su inhibición en materia política, sino hasta su oposición a cualquier lucha en este sentido:

"...cualquier maniobra política que trate de encubrirse con un conflicto laboral debe ser descubierta, combatida y desplazada de los medios sindicales" ${ }^{44}$.

Pero lo más importante, y por lo que la dirección de la CNT tuvo una contestación más fuerte entre la militancia que, hasta el momento, había colaborado con ellos, fue con la publicación de la consulta informe que realizó para definir la táctica a seguir con vistas a la celebración del próximo pleno nacional a celebrar en Madrid, en septiembre de 1968. En ella se señalaba que se seguía apostando por la central única, y hasta se llegó a afirmar que ésta podia ser la actual Organización Sindical Española, al tiempo que informaba que la fracción libertaria se regiría por la organización específica que actuara en el seno de la OSE, y que mantendría "su plena autonomia respecto a toda otra asociación existente o que pueda constituir cualquier tendencia libertaria en la vida española" ${ }^{45}$. Esta declaración suponía el abandono de la organización clandestina y llevaba implícito la desaparición de la CNT. Estos planteamientos supusieron la oposición de buena parte de los militantes con las regionales catalana y levantina a la cabeza, precisamente alli donde la implantación en los sindicatos verticales, desde su origen, fue más acusada ${ }^{46}$.

En medio de estas controversias, se celebró el Pleno Nacional de Regionales que tuvo lugar en Madrid, el 2 de septiembre de 1968, y cuya importancia fue determinante, tanto para el cincopuntismo, como para la situación de la que partió la CNT en el futuro inmediato de la transición de nuestro país a la democracia. Al comicio asistieron las delegaciones de

44 Iritervención de Lorenzo ínigo en el Pleno de militantes de Madrid, el 19 de febrero de 1967. Fondo, Lorenzo Íñigo, carpeta 55, Fundación Salvador Seguí, Madrid.

${ }_{45}$ Fondo, Antonio Barranco, carpeta 98, Funciación Salvador Segui, Madrid.

46 Vease, Actas de la Plenaria del Comité Regional de Alicante. Archivo personal de Celedonio Aparisi. 
Centro, Aragón, Levante, Cataluña, Norte, Asturias y las provincias de Murcia y Alicante que reforzaron a su respectiva región, y credenciales de Buenos Aires y México. El primer punto a tratar fue la discusión del informe que presentó el Comité Nacional. La idea fundamental del documento era querer hacer ver a los delegados el avance que se podía obtener, en el seno del sindicato vertical, si no fuera por la carga negativa que representaban las siglas CNT para los representantes del régimen. Se puso el ejemplo de que con vistas al congreso sindical verticalista celebrado en Tarragona, Solís se puso en contacto con ellos pidiéndoles una representación cenetista compuesta por cuarenta y cinco miembros, pero que dicha iniciativa se tuvo que suspender por la oposición de otros sectores franquistas. Con lo que al final del informe se presentó, sin tapujos, la opción que proponía el Comité Nacional:

«llegamos al punto más delicado de la cuestión y ante el cual no caben rodeos por nuestra parte ¿Cómo tal CNT organizada podemos ser oídos por los dirigentes del actual sindicalismo? Rotundamente no..." ${ }^{4}$.

Y es que para Íñigo y Royano, la CNT, a estas alturas, era un lastre del que tenían que desprenderse. Ya en el transcurso de su gestión habían dado pasos que conllevaban la desaparición de ciertas señas de identidad de la confederación, unas, quizá, menos importanies como la terminología que utilizaban, más propia de falangistas y católicos que de libertarios, al hablar de: "Sindicalismo humanista" o "una humanística de clara proyección social» ${ }^{48}$; otras, más importantes, que siempre han representado un bastión importante en la actuación confederal, como son las publicaciones, - siempre se ha dicho que alli donde hubiera dos cenetistas aparecía una revista - pues bien, el secretariado de la CNT suspendió su órgano de expresión, "Sindicalismo», porque "al estar en la legalidad mantener un boletín clandestino suponia un riesgo evidente..."; y, las más, centrando toda su actividad, primordialmente, en la burocracia sindical, y abandonando la actuación en la calle, en las fábricas, en los talleres, en definitiva en todos aquellos lugares donde la CNT se había granjeado su historia sindical.

\footnotetext{
47 Informe del Comité Nacional al Pleno. Fondo, Antonio Barranco, carpeta 98, Fundación Salvador Segui, Madrid

48 Dicha terminología era más propia de otras personas y lugares como se comprueba en el discurso que, tildado como de "profunda esencia falangista", pronunció Licinio de la Fuente en la sede del Consejo Nacional, ante Franco y el Príncipe Juan Carlos en la sesión conmemorativa del LX aniversario de la fundación de Falange, el 29 de octubre de 1973. Licinio dijo: "Hemos de hacer realidad un 'humanismo social' que equilibre los avances sociales con el respeto a la dignidad y libertad del hombre, y superando lo errores del capitalismo y del marxismo...".
} 
Los dos dirigentes presentaron sendos informes en el comicio nacional confederal: el primero, el de Royano, titulado "Al Pleno", en el que presentó su dimisión como secretario general de la CNT. El documento hacía una dura crítica a la actuación de la Confederación desde 1931 hasta la fecha, poniendo énfasis en la inoperancia de las posturas puristas que, según su opinión han terminado en el más absoluto de los inmovilismos. Íñigo, en su calidad de secretario político, presentó un estudio de la situación española, titulado "la CNT ante el futuro", en el que, una vez más, insistió en la supuesta democratización del régimen, para continuar justificando su inclusión en lo que él llamaba la «Izquierda Nacional» -término que era frecuentemente utilizado por la burocracia falangista-, y que estaba compuesta por el clero joven, algunos militares y los militantes cenetistas que actuaban en los verticales. Ambos informes tuvieron como denominador común el demostrar que la única solución para la CNT, con vistas al futuro, pasaba por una penetración más decidida en los sindicatos verticales, y por la separación de la organización que trabajaba en dicha estructura, de la que se mantenía en la clandestinidad. Este último planteamiento fue fuertemente contestado por la regional catalana, a la que se adhirió la delegación de Francia, posiciones que no impidieron que el Pleno aprobase que en el vertical no apareciera orgánicamente la confederación; es más, el Pleno reflejó entre sus decisiones que «los compañeros que desempeñan cargos dentro de la Organización Sindical no pueden ostentar cargo alguno dentro de la CNT». Con estos acuerdos, íñigo y Royano abandonaban a su suerte a la organización clandestina. La CNT, aquella que pretendió seguir con las siglas históricas y con la lucha clandestina antifranquista, intentó, en el transcurso del mismo comicio, nombrar un nuevo comité nacional, pero chocó con la realidad de la situación que, en esos momentos, vivia el movimiento libertario.

En efecto, el pleno propuso hasta a cinco compañeros para ocupar el cargo de secretario general, pero ninguno de ellos aceptó. Las causas que se alegaron - como no querer volver a la cárcel y la salud por los años-son basiante representativas de dos de los problemas fundamentales que influyeron directamente en el declive de la organización cenetista: la represión y la vejez ${ }^{49}$. Por lo tanto, no se pudo nombrar el

49 Otro como la definición de una nueva doctrina ideológica, más acorde con los tiempos, fue abordada por el Pleno. El secretario político, Lorenzo Íñigo, propuso «ir directamente a la actualización del pensamiento confederal y métodos prácticos que se desarrollen en la presente coyuntu:ra social». El Pleno aprobó esta propuesta y nombró a varios compañeros para que se constituyeran en comisión, y preparasen una ponencia. Pero esta redefinición cenetista, al igual que el nombramiento del secretariado clandestino, nunca se llevó a efecto. Actas del Pleno Nacional del Interior, Fondo Lorenzo Íñigo, carpeta 55, Fundación Salvador Seguí, Madrid. 
secretariado, y el Pleno decidió buscar algún compañero, en los siguientes días, para ocupar dicho cargo; con posterioridad, su designación se sometería a la aprobación del resto de regionales. Todo intento fue en vano, y el secretariado de la CNT clandestina quedó vacante hasta el final de la dictadura. Esta situación contrastó con el nombramiento de la Comisión Nacional que coordinó la actuación de los compañeros que trabajaron dentro de los sindicatos y que, a diferencia de los que pretendieron seguir en la clandestinidad, contaban con la protección que los representantes franquistas otorgaron a los cenetistas cincopuntistas, por lo que el Pleno nombró, sin ningún tipo de problemas, a sus miembros.

De esta manera, el pleno de 1968 consumó el grave error que se venía prediciendo desde tiempo atrás: el separar en dos a la organización libertaria. Si la CNT clandestina, como queda dicho más arriba, no se recuperó, al ser incapaz de encontrar compañeros que dirigieran la Confederación; la organización "legalista", que se constituyó, sufrió, en un corto espacio de tiempo, la pérdida de muchos de sus efectivos por diversos motivos: en primer lugar, porque a pesar de no estar dispuestos a ocupar cargos de representación en la organización clandestina, los militantes cenetistas no querían que sus siglas desaparecieran, a lo que irremisiblemente abocaba las decisiones del último pleno; y porque los futuros acontecimientos iban a demostrar que los dirigentes cincopuntistas, con Lorenzo Ínigo a la cabeza, participaban en un "juego" con el régimen por el que la mayor parte de esa militancia, que trabajaba desde hacía tiempo en los sindicatos verticales, no había apostado.

En efecto, los cincopuntistas, que habian obtenido pocos resultados positivos en las últimas elecciones, centraron toda su política propagandística en la futura Ley Sindical ${ }^{50}$ de la que decían, recogería el contenido de los famosos cinco puntos. Cuando dicha ley fue aprobada en febrero de 1971, las criticas de todos los sectores de oposición al franquismo, y de las internacionales obreras fue unánime. Estas últimas presentaron un informe a la Organización Internacional del Trabajo en el que, tras hacer especial hincapié en que todos los cargos sindicales no eran elegidos democráticamente, y se seguía obviando el derecho de huelga, señalaban que:

50 Esta nueva ley sindical fue anunciada como respuesta del gobierno español a los llamamientos de la Organización internacional del Trabajo para adaptar la legislación y la práctica sindical en España a los principios y normas de la Internacional. 
"La nueva ley sindical no modifica más que la terminologia de la legislación precedente pero conserva integramente su espíritu totalitario (...) En resumen, todas las actividades sindicales que son legitimas y están amparadas en otros países son ilegales en España, por lo que la CIOSL y la CMT han presentado con fecha 12 de marzo, una nueva queja contra el gobierno español por violación de los derechos y libertades sindicales en base a la nueva ley sindical..." 51 .

Una vez más se comprobaba que el régimen franquista seguía en su inmovilismo secular, por mucho que íñigo y los pocos acólitos que, a principios de los setenta, continuaban con él, siguieran defendiendo la "evidente evolución democrática del régimen", y no dudaran en aseverar: «que las reformas dadas al Sindicalismo nacional por la nueva ley son notables y positivas" ${ }^{52}$. Tras el fracaso obtenido, la Comisión Nacional de Coordinación Sindical redactó un informe-temario que fue distribuido entre las regionales para poner las bases de la nueva andadura. El título del documento era: "Final de una etapa con esperanzas de futuro", y significó el fin, teórico, de la era cincopuntista que comenzó en 1965; y digo teórico, porque, en realidad, las propuestas que en él se recogen son una continuación de las que había llevado a cabo la organización desde 1965. En efecto, en las contestaciones que se recibieron de las Comisiones de Coordinación Regionales se seguía defendiendo la penetración en el sindicato vertical, así como la labor de formación entre los trabajadores para que en una primera etapa se lograra implantar las aspiraciones completas de los cinco puntos, y en la posterior, en un alarde de utilización de la nueva terminología, supusiera la consecución de un "socialismo de rostro humano como meta definitiva del sindicalismo obrero». Por lo demás, se incidía en la separación orgánica, aprobada en el Pleno de 1968, de esia línea de actuación con respecto a la clandestina

"Que la actuación de nuestros militantes dentro de los sindicatos se mantenga e incremente todo lo posible, pero que en esta línea no aparezca orgánicamente la CNT» ${ }^{53}$.

Con este programa que, como se aprecia, era una continuación del anterior, siguieron concurriendo a las elecciones sindicales que se celebraron

51 Declaración de la CIOSL y la CMT sobre la ley sindical de 1971, de fecha 18 de marzo de 1971. Fondo, Luis Altable, carpeta 66. Fundación Salvador Seguí, Madrid.

52 Dossier de la Comisión Nacional de Coordinación Sindical, publicado en agosto de 1971. Fondo, Lorenzo Íñigo carpeta 55, Fundación Saivador Segui, Madrid.

53 Comisión Nacional de Coordinación Sindical, Programa Sindicalista. Publicado el 31 de agosto de 1971, sin catalogar. FSS. Madrid. 
en los años 1971 y 1975. El cincopuntismo estaba agotado, como lo estaban los dirigentes que lo habian abanderado desde 1965, y que habian ido sufriendo, según la institución franquista les tragaba ${ }^{54}$, una transformación paulatina. El régimen franquista les terminó tratando con esa mezcla de desdén y paternalismo tan típica de la dictadura:

"La influencia de miembros de la CNT en lo sindical, es escasa; algunos tenemos, y algunos son procuradores en Cortes. Creo que son una aportación espiritual, ellos tienen un patrimonio espiritual muy importante, $y$ el hecho de contrastar con ellos, lo que estamos intentado hacer $y$ de que forma no se traiciona el espíritu sindical de otros tiempos, creo que es importante. Por tanto creo que es importante tanto el atraerlos como el saber lo que piensan por la tradición de que, en cierta medida, ellos son depositarios" 55 .

Lejos quedaba la idea de entrar en los sindicatos verticales para luchar por su democratización y, al mismo tiempo, para revitalizar la CNT. En el camino se habían dejado muchas cosas, entre otras, la más importante, la organización clandestina, aquella que habia mantenido una lucha heroica contra el franquismo. Ahora, éstos que soñaron con derrocar a la dictadura de Franco terminaron "subidos» en el aparato vertical, y acabaron defendiendo dicha institución como la más adecuada para el periodo democrático próximo a comenzar. Esta posición contrasta con la de aquellos militantes cenetistas que trabajaron durante largos años en los sindicatos oficiales y que, aunque en un momento determinado se unieron al "carro cincopuntista" con la revitalización que esto supuso para la organización, no dejaron de hacer su labor sindical en la base, en los tajos donde se encontraban los trabajadores, ocupando cargos de enlace y, por lo tanto, lejos de los tratos con altos dignatarios franquistas. Hay que constatar que, en muchas ocasiones, fue precisamente allí, donde la penetración en el vertical se hizo por la base, donde el resurgimiento de la CNT fue más rápido y cuantioso ${ }^{56}$. La sombra del cincopuntismo se alargó más allá del fin de la dictadura, y no faltaron las acusaciones de "cincopuntista", contra algunos militantes, en la nueva reorganización cenetista.

54 Lorenzo Íñigo formó parte del jurado para el premio «Larra» que estuvo compuesto por Ramón Serrano Suñer, Manuel Blanco Tobío, Ricardo de la Cierva, Gregorio del Toro, Emilio Romero, Jaime Delgado, Dámaso Santos, Urbano Orad y Lorenzo ínigo, como secretario Julio Merino. Diario "Arriba". 8 de marzo de 1974.

55 Entrevista a Rodolfo Martín Villa en "El Correo Catalán", 28 de marzo de 1971.

56 Véase el informe que realizó Fidel Miró sobre la situación de la CNT en España en 1976 , Archivo, Gómez Peláez. Instituto Internacional de Historia Social de Amsterdam. 


\section{EL CINCOPUNTISMO EN EL EXILIO}

Los vientos que soplaban en el exilio a la altura de 1965 estaban, una vez más, bastante enrarecidos. Con la reunificación de 1961, tras dieciséis años de escisión, el movimiento libertario parecía haber tomado un fuerte impulso, y fruto de ello fue la puesta en marcha de varias iniciativas que dieron una imagen de resurgimiento: la constitución de la Alianza Sindical, el intento de creación del Frente Antifascista Español y la formación de Defensa Interior. Pero con excepción de la primera de ellas, que llegó hasta la transición democrática en nuestro país, las otras dos tuvieron una vida efímera: el Frente fue "non nato", al igual que pasó en 1952 y en 1960 , al no ser secundado por ninguna otra organización antifranquista; y el organismo de acción, por la falta de medios y el fuerte enfrentamiento que provocó en el seno de la organización ${ }^{57}$. Fue, precisamente, la discusión sobre Defensa Interior en el año 1965, durante la celebración del Congreso que la organización cenetista convocó en la localidad francesa de Montpellier, uno de los dos problemas que influyeron sobre manera en el devenir inmediato de la organización anarcosindicalista en el exilio, y que supuso el primer acto de la futura escisión dentro del movimiento; el otro, fue el cincopuntismo, que tomó carta de naturaleza, en el exilio, con la visita al citado Congreso de Royano, como representante del Comité Nacional del Interior, para hacer participe a la organización del exilio de las conversaciones iniciadas en Madrid.

Con respecto a la primera cuestión, el Congreso puso el punto y final a Defensa Interior, pero antes tuvo que hacer frente a las impugnaciones que Cipriano Mera y Octavio Alberola habían formulado, por malversación de fondos y obstrucción de la labor a desarrollar por el citado organismo, contra Germinal Esgleas y Vicente Llansola. En el debate, los acusadores pasaron a ser los acusados, y se libraron de la expulsión, de momento, "en aras de la armonía orgánica y del movimiento" ${ }^{58}$. Esta resolución provocó la protesta de un buen número de militantes que no estaban de acuerdo ni con el contenido del acuerdo, ni con el sistema de votación que se había utilizado para su aprobación, lo que supuso el abandono del comicio de militantes y de las Federaciones Locales de Paris, Toulouse, Colomiers, Narbone, Cahors, Macau, Neuphle-le-Vieux y Londres.

57 Véase, Alberola, Octavin y Gransac, Ariane, El anarquismo español y la acción revolucionaria 1961-1974, Francia, Ruedo Ibérico, 1975.

58 Actas de la sesión privada del Congreso de Montpellier, que se desarrolló del 5 al 7 de agosto de 1965. Fondo Gómez Peláez, Instituto Internacional de Historia Social de Amsterdam. 
En cuanto a la presencia de Royano en Montpellier, se puede decir que pasó por todo tipo de vicisitudes: en primer lugar, tuvo dificultades, desde su llegada a la ciudad francesa con la dirección del exilio, que no quería que el representante del interior interviniera en el congreso. Al final, se llegó a un extraño acuerdo consistente en que Royano se presentara ante los delegados del comicio sólo para exponer la situación del interior, y sin la posibilidad de que ningún delegado le formulara pregunta alguna. Por otro lado, el representante del interior tuvo un encuentro con los militantes que, como hemos visto anteriormente, abandonaron el Congreso, a quienes les hizo partícipes de la misión principal que le habia llevado a Francia a través de un documento titulado: "Una gestión transcendental». El informe hacía un repaso pormenorizado de las diferentes entrevistas que habian tenido lugar entre cenetistas y franquistas, y el momento actual de las negociaciones. La cuestión del conocimiento de las conversaciones con los franquistas, y su ocultación al congreso, ya fuera antes del cónclave cenetista por parte del Secretariado Intercontinental, con Esgleas a la cabeza; o durante el transcurso del mismo, por parte de los que habían abandonado el comicio como: José Peirats, Ramón Álvarez, Cipriano Mera..., supuso el centro del primer debate que entrentó a los dos grupos en los que, desde este momento, se volvió a dividir la organización.

Efectivamente, el Secretariado Intercontinental lanzó una campaña contra los que se ausentaron del Congreso acusándoles de traidores, por conocer las negociaciones que estaban teniendo lugar con los franquistas y no haber informado a la organización reunida, y lo que era más grave, el estar de acuerdo con ellas. Lo cierto es que los que salieron del congreso tuvieron una reunión con Royano, al que le hicieron llegar su oposición a dichas conversaciones, $y$ al que conminaron a no hacer lectura de su documento ante los delegados presentes en el congreso:

"Yo estuve hablando con el delegado del interior y entre todos los amigos conseguimos que no se presentara en el congreso con ese plan suicida...pero nos costó mares de sudores evitar que fuera con ese plan al congreso" 59 .

Por su parte, éstos también acusaron a la dirección cenetista de conocer las susodichas negociaciones con bastante anterioridad del inicio del Congreso de Montpellier. Así, esgrimieron una carta que había enviado Enrique Marco a Germinal Esgleas en la que le decia haber recibido la

59 Carta personal de Peirats a Gómez Peláez, de fecha 17 de septiembre de 1965. Fondo, Gómez Peláez, Instituto Internacional de Historia Social de Amsterdam 
visita de un enviado del secretario general del exilio el pasado 23 de julio, y, mediante el cual, le pedía corroboración de las negociaciones que tenian lugar en Madrid, y de las que Esgleas había sido informado, directamente, por un funcionario del Estado Español desplazado en Suiza ${ }^{60}$.

El enfrentamiento se trasladó a toda la organización, y en las federaciones locales y núcleos del exilio tuvieron lugar reuniones donde se repudiaron las conversaciones y se pidieron responsabilidades por la falta de información al Congreso. En algunos lugares, los menos, principalmente en las federaciones locales donde sus representantes abandonaron el Congreso, se pidió "cuentas» al Secretariado Intercontinental; sin embargo, prácticamente en la totalidad de los plenos de Núcleos, a quien se culpó de ocultación y hasta de apoyar las negociaciones de Madrid fue a aquellos que tuvieron la entrevista con Royano. Desde ese momento, este grupo, conjuntamente, con los que en un futuro próximo apoyaron las conversaciones de Madrid y con todo aquel militante que se opusiera a la línea que marcaba la dirección, encabezada por el Secretariado Intercontinental, sufrió una persecución implacable que acabó con su expulsión de la CNT. En palabras de Lucas Sánchez:

"Los ortodoxos tomaron aquel desafortunado intento como caballo de batalla que justificara el inicio de las expulsiones..." ${ }^{61}$.

Un ejemplo representativo, de la convulsión que vivió el movimiento libertario desde el comicio de 1965, fue lo acontecido en la Federación Local de Burdeos, allí uno de los asistentes a la reunión con Royano, Torremocha, tuvo que hacer frente a las acusaciones de "cincopuntista" y ocultación, por no informar al Congreso sobre las negociaciones de Madrid. Pues bien, después de negar en repetidas ocasiones su apoyo a las negociaciones de Madrid, terminó siendo expulsado de la organización, y con él quince compañeros que le apoyaron ${ }^{62}$. En las actas del siguiente Pleno Intercontinental, que celebró la Confederación en Marsella en agosto de 1967, se recogió la situación de enfrentamiento que, en algunos casos, supuso la separación orgánica de federaciones locales enteras. Así, la federación local de Les Salvages, a raíz de la expulsión de R. Martínez se disolvió. En Provenza, la federación local de la Rose se puso al

60 Carta de Enrique Marco a Germinal Esgleas, de fecha 23 de agosto de 1965. Fondo, Antonio Barranco, carpeta 98, Fundación Salvador Seguí, Madrid.

63 Carta de M. Sánchez Lucas, desde Beziers, de fecha 15 de octubre de 1999

62 Informe de la Federación Local de Burdeos sobre marginalismo, de fecha 13 de marzo de 1966 Fondo, José Payán, sign., 2-14, Fundación Salvador Segui, Madrid. 
margen de la organización... ${ }^{63}$. Las expulsiones alcanzaron a militantes del otro lado del Atlántico, y en México se expulsó a los compañeros Fidel Miró, R. Magriña, Joaquín Cortes, Santiago Bilbao, Juan Rueda Ortiz...

De todas formas, al igual que sucedió en el interior, se puede decir, sin ningún género de dudas, que la inmensa mayoría de la militancia del exilio estuvo en contra de las negociaciones cincopuntistas. Aunque, no es menos cierto que una parte de esa militancia discrepaba, principalmente, por la forma de llevar a cabo las negociaciones, y, sin embargo, apoyaba la táctica de penetración por la base en los sindicatos verticales:

«El cincopuntismo: mi opinión es, y creo que ello refleja el de la organización en general, que aquella operación no era aceptada ni podía ser aceptada por la militancia. Estábamos de acuerdo en que a título personal los militantes se integraran en los sindicatos verticales para hacer prosélitos con vistas al mañana. Pero no podiamos aceptar un pacto o un compromiso con los representantes falangistas del verticalismo $y$, menos aún, con la venia de Franco, como parece que era el caso" ${ }^{64}$.

Sin embargo hubo un grupo de militantes, minoritarios en el exilio, que apoyó sin ningún tipo de ambigüedad las negociaciones con los verticalistas. Este grupo tomó el nombre de "Amigos de la CNT España". Su origen tuvo lugar en una reunión que se celebró en Thil el 14 de julio de 1966, a ella asistieron diferentes grupos de militantes exiliados inclusive de fuera de Francia. En esta primera reunión se acordó: apoyar y defender la negociación emprendida por la CNT del interior, y prestarle todo el apoyo posible tanto material como humano, nombrar una Comisión de Coordinación con sede en Toulouse, que asegurase la agilidad de las relaciones, y potenciar las revistas "Sindicalismo", que era el boletín del Comité Nacional cincopuntista en el interior, $y$ «Proyección» revista que éste grupo exiliado publicó en Francia. La primera Comisión Coordinadora quedó compuesta por: Felix Carrasquer ${ }^{65}$, en el cargo de secretario general; Severiano Álvarez, vicesecretario; José Domínguez, administrador; el resto de compañeros que completaron el secretariado, fueron elegidos con pos-

63 Actas del Pleno Intercontinental de Núcleos celebrado en Marsella en agosto de 1967. Fondo, Ángel Marcos, sign., 33-2, Fundación Salvador Segui, Madrid.

64 Carta de José Borrás, desde Toulouse de fecha 4 de octubre de 1999.

6.5 Militante que era ciego, nació el 4 de noviembre de 1905. En 1936 fue miembro del Comité Peninsular de la FAI. Perteneció a diferentes comités regionales y nacionales, y fue detenido el 15 de noviembre de 1947. Carrasquer fue condenado a 25 años de cárcel, permaneciendo en la cárcel 12 años. Fue puesto en libertad en 1959. En 1960 pasó a Francia, regresando a España como consecuencia de la operación cincopuntista. Ocupó diferentes cargos en la organización sindical franquista volcando su actividad en los cursos de formación de los representantes sindicales. 
terioridad ${ }^{66}$. En una reunión que se celebró en París el 12 de marzo de 1967, tuvo lugar la elección de una nueva comisión compuesta por: Antonio Barranco, como secretario general; Martín Alandi, vicesecretario; Severiano Villa, secretario de administración -que, por motivos de trabajo, fue sustituido por Emilio Badia en julio de 1967-; Helenio Molina, secretario de prensa y propaganda; Progreso Martínez, secretario de relaciones ${ }^{67}$. Desde este momento, el lugar de residencia del nuevo secretariado fue París. Felix Carrasquer, antiguo secretario, se trasladó a España, en donde residió, ocupando el cargo de Delegado de la Comisión Coordinadora en el Interior. Estos militantes exiliados, en sintonía con los del interior, se mostraban especialmente críticos con la actuación del exilio, del que decian que había sufrido un "egocentrismo" que le hizo creerse "el poseedor de la verdad en nombre de una historia quizás gloriosa, pero ya pasada» ${ }^{68}$. Por lo tanto, según su apreciación, había que actualizar la central anarcosindicalista y sacarla de la situación extremadamente crítica por la que atravesaba consecuencia del divorcio existente entre el pasado y el presente, para lo cual estaban a favor de la penetración en los verticales y defendian las negociaciones cincopuntistas. En mayo de 1967, quizá el momento más álgido del grupo, la Comisión Coordinadora de "Amigos de la CNT de España", sacó un documento en el que hizo un resumen de las agrupaciones y los militantes que estaban adheridos a la organización. En total eran veintiuna las Agrupaciones que existían en Francia con un total de ciento cincuenta y tres militantes adheridos -en esos momentos la organización del exilio contaba con unos cuatro mil afiliados-, el mayor número de militantes estuvo en Marsella con cuarenta, seguida de París con veinte ${ }^{69}$.

La reacción de el Secretariado Intercontinental, capitaneado por Esgleas, se dirigió en una doble dirección: por un lado, su actividad se centró en el exilio aprovechando la situación creada por el cincopuntismo, como hemos visto más arriba, para imponer su línea de actuación definitiva-

66 Circular n." 1 de "Amigos de la CNT de España», fecha 30 de julio de 1966. Fondo, Antonio Barranco, carpeta $86, n \cdot{ }^{\circ} 2$, Fundación Salvador Segui, Madrid.

67 Circular n. ${ }^{\circ} 6$, de fecha 19 de marzo de 1967, Fondo, Antonio Barranco carpeta 86 n. 8 , Fundación Salvador Segui, Madrid.

68 Comunicado de la Comisión Coordinadora, 19 de marzo de 1967, Fondo, Antonio Barranco carpeta 86 n." 9, Fundación Salvador Seguí, Madrid.

69 En el mismo documento se hacía mención a urıa serie de militantes en el exilio que habian mostrado su simpatía aunque sin integrarse a la nueva crganización como: Francisco Carrasquer, en Holanda y Félix Lorenzo Páramo, en Suiza. Otros mostraron su total identificación, como Antonio Muntaner, en Roma; Fidel Miró, Jaime R. Magriña, Joaquín Cortés y Juan López en México; Abad de Santillán, Manuel Villar, Pedro Herrera y Jacinto Torhyo desde Buenos Aires. Fondo, Antonio Barranco, carpeta n. 86, n. 13, Fundación Saivador Segui, Madrid. 
mente; por el otro, hacia el interior con vistas a volver a controlar la organización de España, mediante la constitución de un comité nacional favorable a la dirección del movimiento en el exilio. En efecto, el Secretariado apoyó a un grupo de cenetistas en Santander, donde se constituyó, en un principio, una comisión nacional de relaciones para ponerse en contacto con otras regionales y promover una nueva dirección. Pero todas las negociaciones fueron infructuosas, la realidad de la situación que la organización confederal vivía en España se impuso, y no fue posible, ni tan siquiera, la realización de un pleno en el interior para la constitución de un nuevo comité nacional, por lo que dicha comisión presentó su dimisión. En el intento de crear un nuevo comité nacional, la dirección del exilio llegó a organizar un Pleno Nacional de Regionales de España... en Toulouse ${ }^{70}$, y nombró un comité nacional que, según denunció la regional de Euskadi, fue el mismo que asistió al Pleno de núcleos de Marsella y más tarde al Congreso de la AIT ${ }^{71}$. Por su parte, los "Amigos de la CNT de España" continuó su labor de apoyo a la organización de España, pero, al igual que sucedió en el interior, sus efectivos fueron menguando debido, en gran medida, al cambio de rumbo que fue discerniéndose de las manifestaciones que realizaban los dirigentes en el interior, en las que se dejaba entrever el deseo de poner fin a la organización clandestina:

"Là lógica consecuencia, tras el diálogo, es considerar terminada toda pretensión de continuidad histórica de la CNT como organización» ${ }^{72}$.

O aquellas otras, en las que se anteponía la organización sindical franquista a la CNT, como se desprendía de la inquietante frase de Lorenzo İñigo:

«Resulta evidente que no podemos, a la vez y los mismos hombres, actuar y menos representar a otra organización que está al margen y, en muchos aspectos, enfrentada a la Organización Sindical...» ${ }^{73}$.

70 Llansola, en su intervención en el Pleno de Marsella de 1967 como secretario de coordinación, informó del Pleno de España sin especificar el lugar donde se celebró, aunque señaló que «al elegir el lugar de la celebración del Pleno, se ha tenido en cuenta la eficacia y la seguridad personal del que concurria". Actas del Pleno Intercontinental de Núcleos de Marsella 1967, Fondo, Ángel Marcos, sig. 33-2, Fundación Salvador Seguí, Madrid

74. Memoria Informe de la regional de Euskadi, de fecha 6 de febrero de 1968. Fondo, Ángel Marcos, sig. 01-10, Fundación Salvador Segui, Madrid.

72 La frase es de Juan López, recogida en la carta que enviaron Manuel Villar, Pedro Herrera y Abad de Santillán desde Buenos Aires a Francisco Royano, el 1 de diciembre de 1967. Fondo, Antonio Barranco, carpeta n. 94, Fundación Salvador Segui, Madrid.

73 Correspondencia entre Juan Ferrer y Lorenzo Ínigo, 8 de enero de 1968. Fondo, Antonio Barranco, carpeta n. 94, Fundación Salvador Segui, Madrid. 
Todos estos planteamientos fueron duramente criticados desde todos los lugares del exilio confederal, incluidos los "Amigos de la CNT de España". La contestación tuvo su punto más álgido en las reuniones que tuvieron lugar para discutir la famosa consulta-informe que dirigió el comité nacional del interior, para el pleno que se celebró en septiembre de 1968, en la que se planteaba la idea de la doble estructura separada: por un lado, los que entraban en el vertical; por el otro, los que seguian en la organización clandestina. $Y$ aunque este grupo seguía defendiendo el «espíritu de los cinco puntos", y apoyando la táctica de penetración en los sindicatos oficiales, la militancia era consciente de que no se habian cumplido ninguno de los objetivos que la negociación cincopuntista pretendió, por lo que no faltaron los militantes que pidieron la dimisión del Comité Nacional del interior, ya que esta proposición la consideraban como el fin de la organización anarcosindicalista, aquella por la que habian dado toda su vida. Fue necesario redactar una proposición que mantuviera el contacto entre las dos organizaciones para que el dictamen del Comité Nacional fuese aprobado por las veintidós agrupaciones existentes, en ese momento, en Francia; pero el resultado de la votación, con 62 votos a favor, 28 en contra, 3 con la mayoría, y 14 sin opinar, muestran claramente la profunda división entre los ya escasos militantes que, todavía en el exilio, seguían apoyando a los dirigentes cincopuntistas, y que después de esta situación quedaron, todavia, mucho más mermados. La opinión, y futura actuación de muchos de estos militantes, se puede resumir en las palabras de Lola Iturbe:

"Para que desaparezca la CNT y se intente diluir en los sindicatos verticales para afianzarlos y con ello afianzar la situación actual del régimen español, a eso, digo jno! (...) Como se que dejáis la iniciativa libre a quien quiera y se atreva a organizar la CNT al margen de los sindicatos verticales por su cuenta y riesgo, yo doy mis simpatías a esa iniciativa» ${ }^{74}$.

Aquellos pocos militantes que siguieron apoyando, desde el exilio, a los dirigentes cincopuntistas, vieron como el paso del tiempo dio la razón a los compañeros que entendieron que tras los acuerdos del Pleno celebrado en España en septiembre de 1968, se encontraba el fin de la CNT como organización en España durante el franquismo. Felix Carrasquer, uno de esos dirigentes cincopuntistas, lo llevaba más allá, al profetizar que «la CNT ha muerto y nadie podrá resucitarla» ${ }^{75}$.

74 Carta de Lola lturbe, compañera de Juan M. Molina, al Comité Nacional del interior, de fecha 27 de enero de 1968. Fondo, Gómez Peláez, Instituto Internacional de Itistoria Social de Amsterdam.

75 Carta de Felix Carrasquer a Antonio Barranco, fecha 24 de febrero de 1969. Fondo, Antonio Barranco, carpeta 94. Fundación Salvador Segui, Madrid. 


\section{CONCLUSIONES}

Las negociaciones que tuvieron lugar a principios de la década de los sesenta entre burócratas falangistas y viejos cenetistas, hay que encuadrarlas en la profunda crisis que ambas organizaciones, en otra época poderosas, estaban atravesando por la aparición, en sus respectivos círculos de influencia, de otros grupos más adaptados a las nuevas realidades. Si en el caso de los primeros, eran los tecnócratas los que tomaban, en estos años, el liderazgo dentro del régimen franquista; en el mundo obrero era las Comisiones Obreras, con una implantación cada vez mayor en su seno de elementos comunistas, las que despuntaban en el panorama sindical español. Las ansias de recuperar el terreno perdido supuso que ambos grupos, a pesar de que los intereses de unos y otros eran profundamente dispares, convergieran en la necesidad de un pacto que, a los primeros, les permitiera recuperar su prestigio y poder; mientras que para los segundos, significase su resurgimiento con vistas a la nueva etapa que estaba pronta a iniciarse.

La organización cenetista estaba, en estos años, desectructurada. La represión habia golpeado tan duramente a sus cuadros militantes, que la mayoría de ellos vivía en un "exilio interior» sin llevar a cabo ninguna actividad orgánica; por otra parte, no había tenido lugar la tan necesaria renovación generacional de militantes, por lo que sus dirigentes contaban, en su mayoría, con una edad avanzada. Estos viejos cenetistas pretendieron hacer renacer la organización anarcosindicalista mediante dos líneas de actuación: una ajena a su tradición, basada en los resultados positivos que los comunistas estaban cosechando, como era la penetración en los sindicatos verticales; y otra, más ligada a su idiosincrasia, mediante la educación de los jóvenes trabajadores en la teoría anarcosindicalista. Pero para llevar a cabo este plan necesitaban, en primer lugar, la formalización de un pacto con las autoridades franquistas que les permitiera llevar a cabo su actividad a salvo de la represión. Esta cuestión, y la necesidad de recuperar, lo más rápidamente posible, el espacio y el tiempo perdidos, les llevó, en primer lugar, a plantear las negociaciones, y, más tarde, al famoso acuerdo de los cinco puntos, en noviembre de 1965.

El pacto fue duramente criticado, tanto desde las organizaciones de oposición al franquismo como en el seno del anarcosindicalismo. Aunque para la CNT en el interior, en manos de Francisco Royano y Lorenzo Ínigo, la puesta en marcha de este plan significó, en su primera etapa, la reestructuración y coordinación de la organización cenetista, y su implantación en un buen número de regiones, en las que desde hacia tiempo no existia presencia orgánica confederal. De hecho, este grupo negociador se puso 
en contacto con muchos militantes cenetistas que, a título personal, estaban ejerciendo su labor sindical en el seno de la organización vertical, y que habian actuado, hasta la fecha, sin ninguna conexión entre sí, es más, en muchos casos con el rechazo de la organización y de un buen número de compañeros.

En su evolución, esta nueva organización, que pretendía la democratización de los sindicatos oficiales, fue perdiendo el entusiasmo inicial, en algunas ocasiones, porque los resultados de las diferentes elecciones sindicales no fueron lo suficientemente positivos, con el agravante del progreso comunista; en otras, porque los militantes que trabajaban en el vertical, teniendo como base los cinco puntos, comprobaban que no se llevaba a efecto la supuesta evolución democrática de organización franquista; $y$, en definitiva, porque los dirigentes confederales fueron implicándose, cada vez en mayor medida, en los sindicatos oficiales, hasta el punto que la CNT llegó a suponer una carga para ellos. El momento álgido de esta situación tuvo lugar en el pleno que la organización cenetista celebró en España en 1968 que supuso el fin de la organización clandestina que, desde 1939, había llevado a cabo su lucha contra el franquismo, al no poder constituir el secretariado que dirigiera la organización en los momentos cruciales del cambio de régimen en España, lo que supuso para la Confederación el iniciar, dicho período, rezagada con respecto a las demás organizaciones.

En definitiva, la organización cenetista chocó, para hacer efectiva su revitalización, con diferentes problemas: unos viejos, como el anticomunismo que cegó, en gran medida, la inteligencia de estos militantes; otros de apreciación, al creer en la evolución democrática del régimen franquista; y otros tácticos, al ir centrando cada vez más su actividad, única y exclusivamente en los sindicatos verticales, con el consiguiente abandono de la labor clandestina, tan necesaria para granjearse la confianza de los trabajadores. Así, del supuesto renacer de la organización se pasó al desprestigio que supuso para la CNT su experiencia cincopuntista, y cuyas repercusiones fueron todavía más importante al estar tan próxima la transición democrática en nuestro país. 